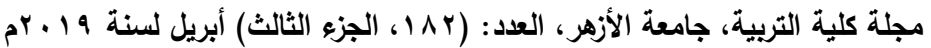

تحليل محتوى كتب الفيزياء في المملكة العربية السعودية في ضوء التصميم

الهندسي لمعايير الجيل القادم للعلوم NGSS

$$
\text { مها بنت فراج البقمي، جبر بن محمد الجبر }
$$

قسم المناهج وطرق التدريس، كلية التربية، جامعة الملك سعود، الرياض، المملكة العربية

البريد الاكتروني: m-aahi@hotmail.com

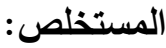

هدفت الدراسة الحالية إلى تحليل محتوى كتب الفيزياء في المملكة العربية

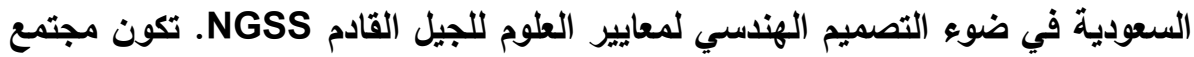
الدراسة من جميع كتب الفيزياء المقرة للمرحلة الثانوية -نظام مقررات-، وتكونت فئن عينتها من جميع الأنثطة المقرة في تلك الكتب. ولتحقيق هدف الدراسة استخدم الباحثان

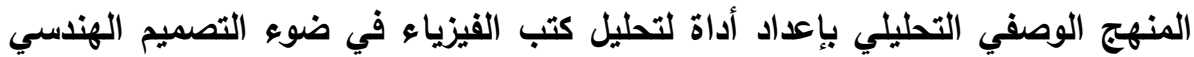

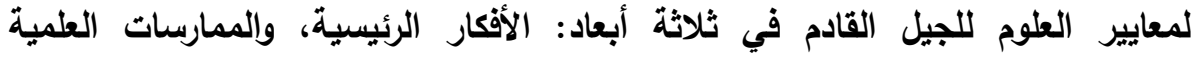

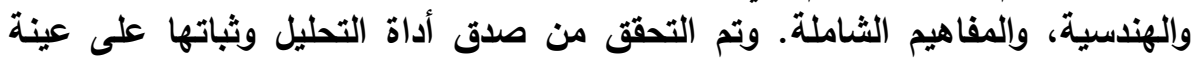
استطلاعية. توصل الباحثان بعد إجراء عملية التحليل إلى نتائج من أهمها: تحقئ التهائ الأبعاد

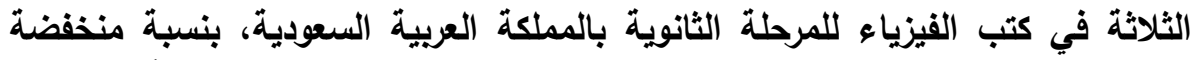
بلغت (Tr.Mr\%)

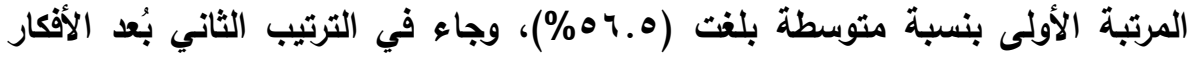

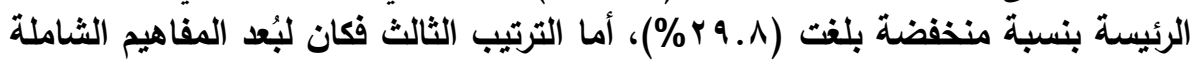

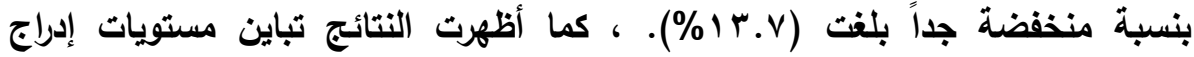

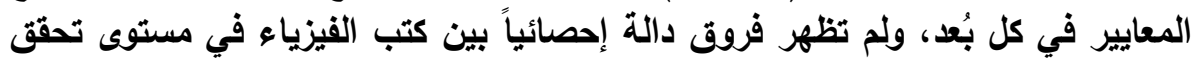
معايير التصميم الهندسي بمشروع معايير الجيل القادم لتعليم العلوم.

الكلمـات المفتاحيـة: تحليـل محتـوى، التصميم الهندسـي، معـيير العلـوم للجيـل القـادم

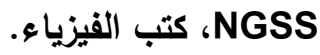


تحليل محتوى كتب الفيزياء في الملكة العربية السعودية في ضوء التصميم الهندسي لمعايير الجيل ل... أ. مهاً بنت فراج البقمي، أ. د. جبر بن محمد الجبر لئر

Analysis Content of Saudi Arabian Physics Textbooks in the Light of Engineering Design of Next Generation Science Standards

* Maha F. Albogami \& Jabber M. Aljabber

Curriculum and Instructions Department. Faculty of Education, King Saud University. KSA.

*Email: $\underline{\text { m-aahi@hotmail.com }}$

Abstract:

This study aimed to analyze content of physics textbooks according to Engineering Design of Next Generation Science Standards (NGSS). Population of the study consisted of all physics textbooks in secondary stage (course system), while its sample consisted of all the activities in physics textbooks. To achieve the aim of the study, a descriptive analytical method was used, through designing analysis tool based on engineering design of the NGSS in three dimensions, namely: Disciplinary Core Ideas, Science and Engineering Practices, and Crosscutting Concepts. A pilot study was conducted to assure the validity and reliability of the analysis tool. The overall results showed that all three dimensions was included in all physics textbook, with low percentage of $(33.33 \%)$. More specifically, Science and Engineering Practices was the most included dimension with (56.5\%), followed by Disciplinary Core Ideas with $(\mathbf{2 9 . 8 \%})$, ending by Crosscutting Concepts with very low percentage of $(13.7 \%)$. Furthermore, results showed variation of inclusion levels of standards in each dimension. Results found no statistically significant differences between physics textbooks with regard to inclusion level of engineering design standards of the NGSS.

Keywords: Content Analysis, NGSS Standards, Engineering Design, Physics textbooks 


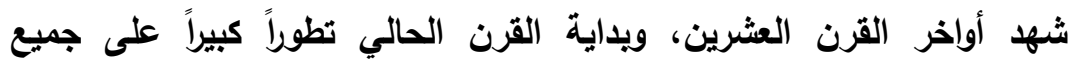

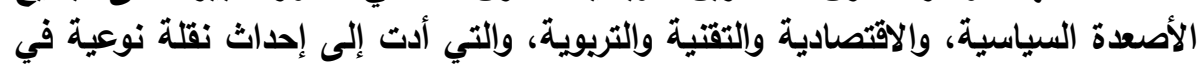

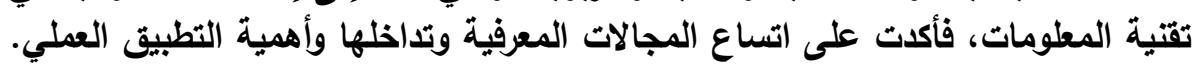

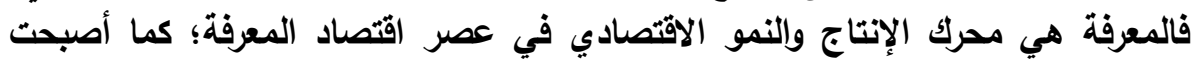

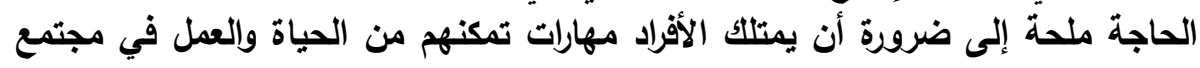
اقتصاد المعرفة.

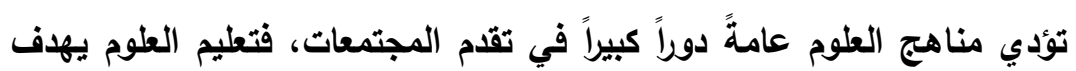

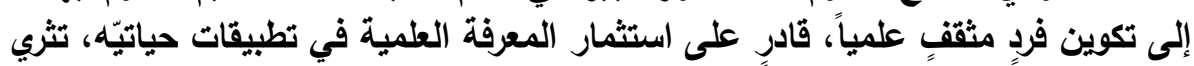

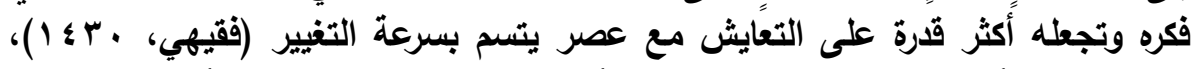

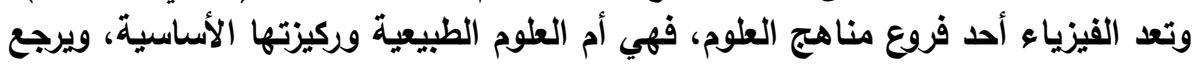

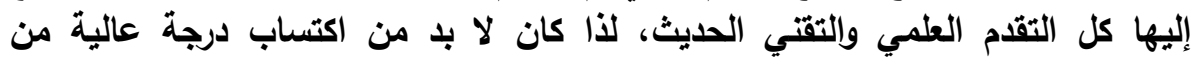

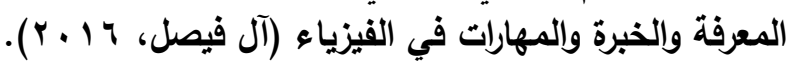

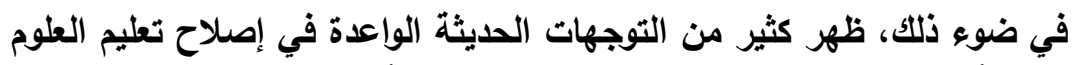

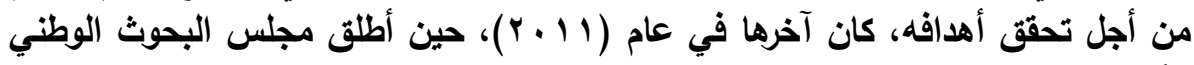

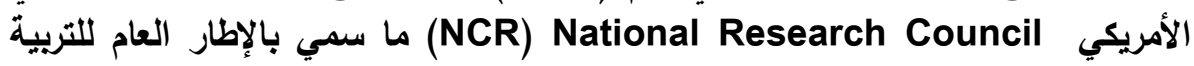

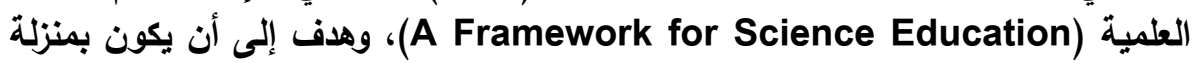

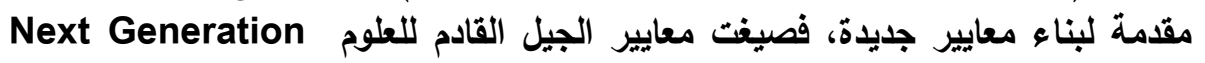
.(NGSS Lead states, 2013) (Science Standers NGSS)

جائت معايير الجيل القادم للعلوم بروئية جديدة مفادها، التأكيا على استخدام

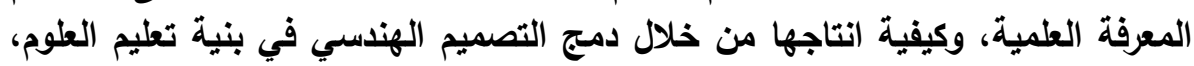

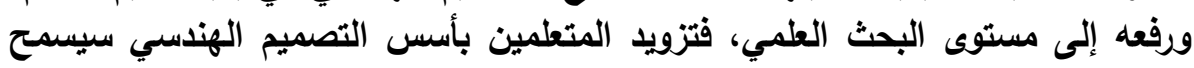

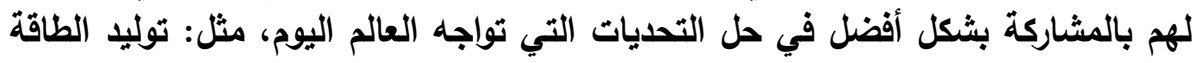

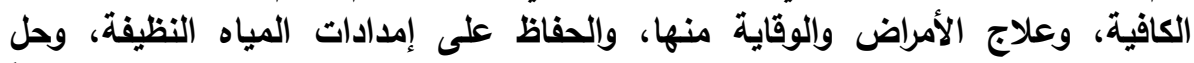
مشكلات التغير البيئي العالمي (NGSS Release, 2013; NRC, 2012). لتلك الروئة، أكد سنيار (Senider, 2012) أنّ إضافة البعد الهندسي في تعليم العلوم

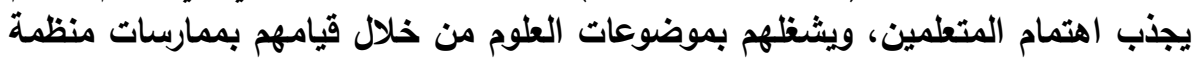

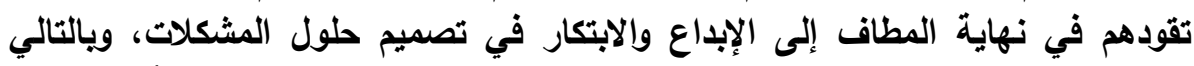

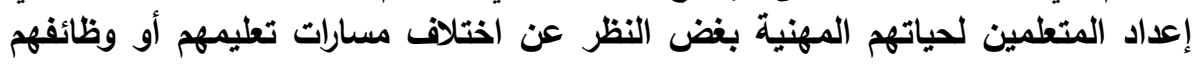

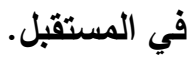




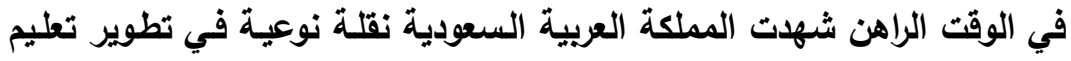

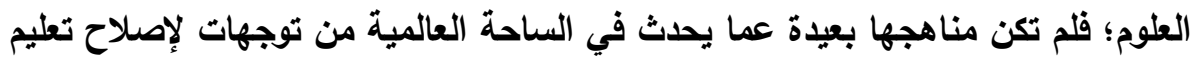

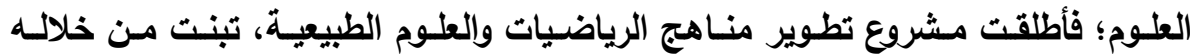

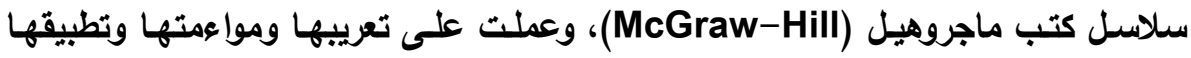

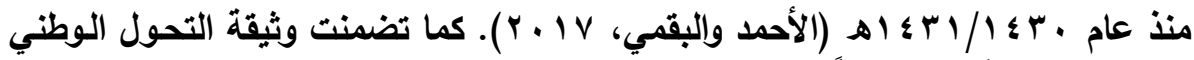

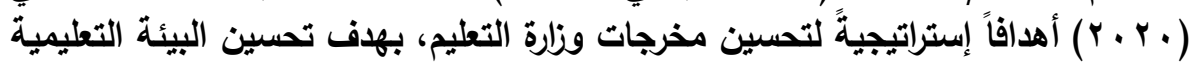

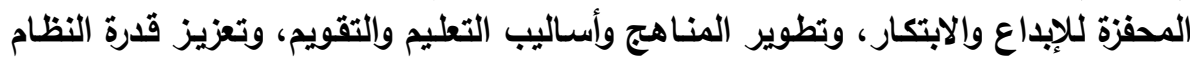

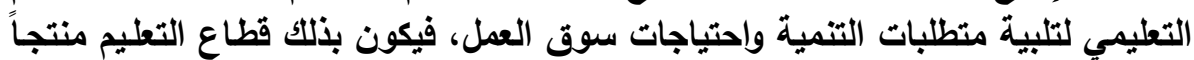

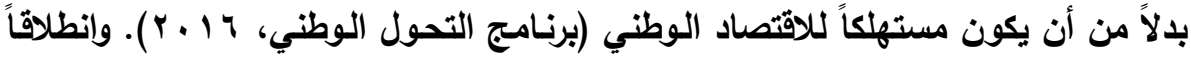

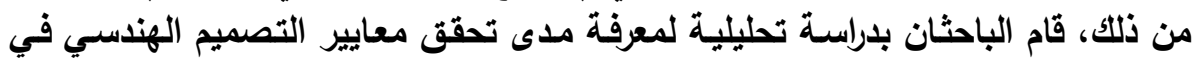

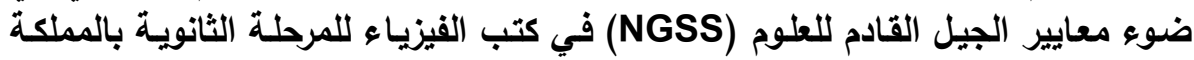

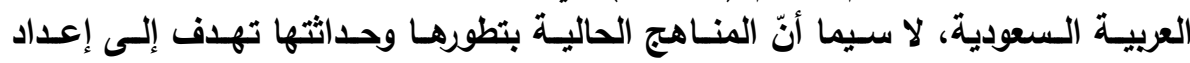
المتعمين الذين يملكون الثقافة العمية التي تؤهلهم لمستقبل واعد في القرن الحادي العادي والعشرين.

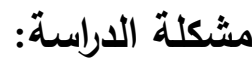

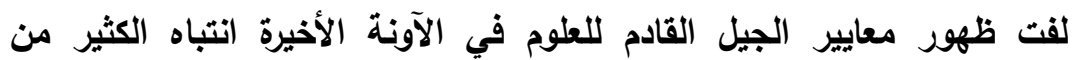

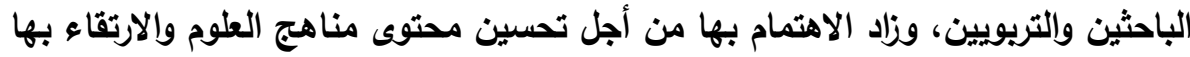

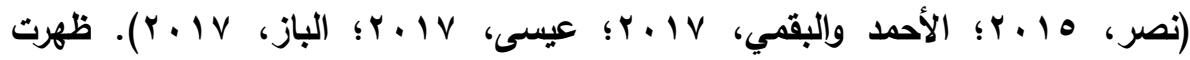
معايير الجيل القادم للعلوم بشكل يميزها عن باقي المشيكي المشروعات والمعايير السابقة، بأنها

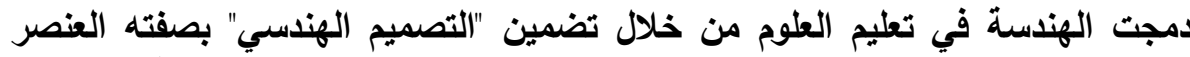

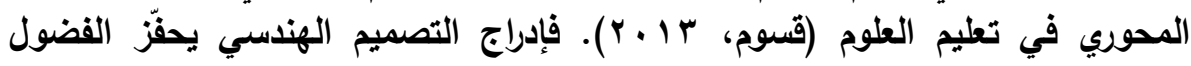

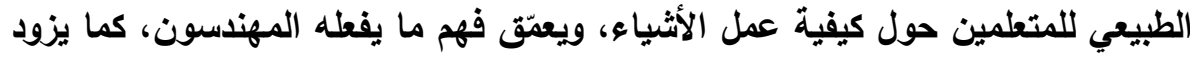

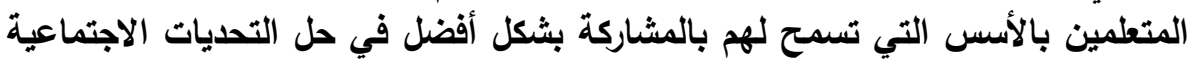

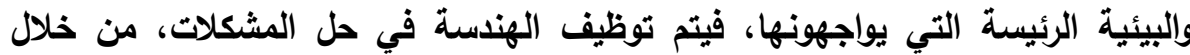

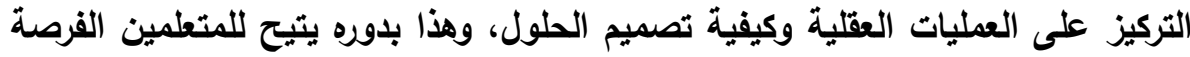

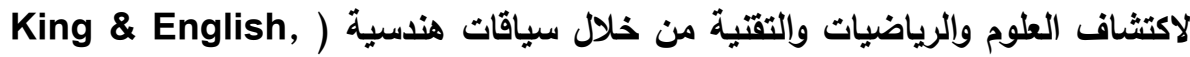
2016; Concannon \& Brown, 2016; Chabalengule \& Mumba,

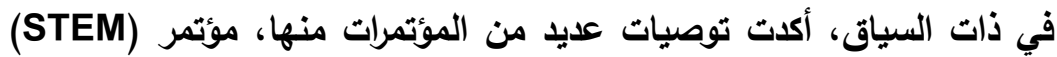

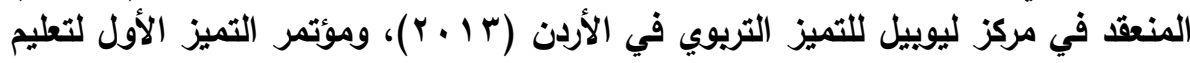




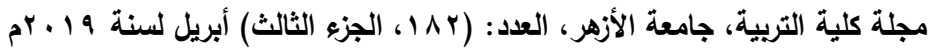

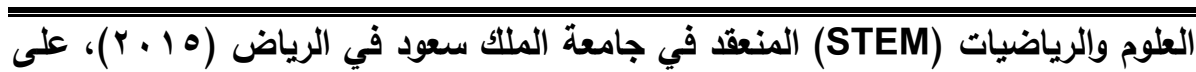

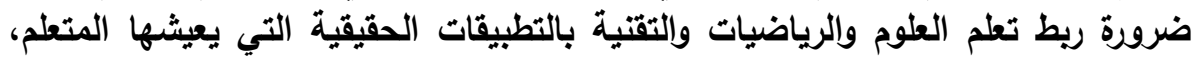
وذلك من خلال التصميم الهندسي.

وياستقراء أهمية التصميم الهندسي ودوره في دفع المتعلمين إلى تصميم حلول

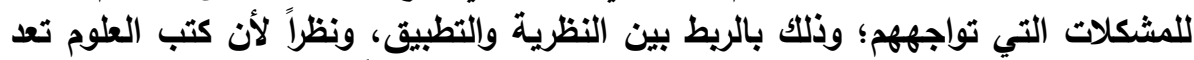

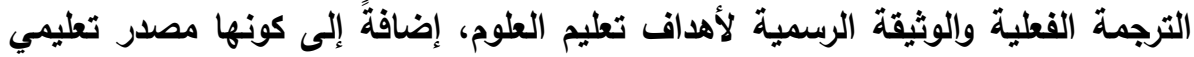

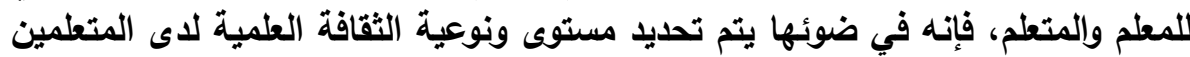

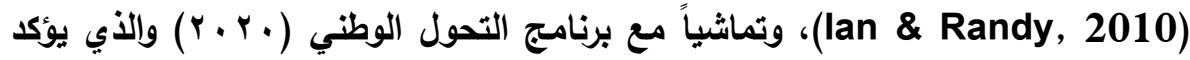

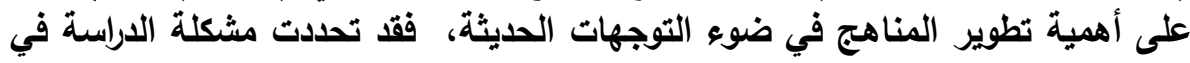

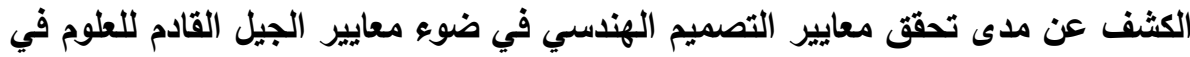
كتب الفيزياء للمرحلة الثانوية. وعليه؛ سعت الديم الداسة إلى الإجابة عن الأسئلة التالية: 1. ما مستوى تحقق معايير التصميم الهندسي في ضوء معايير الجيل القادم للعلوم

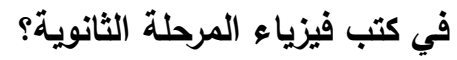

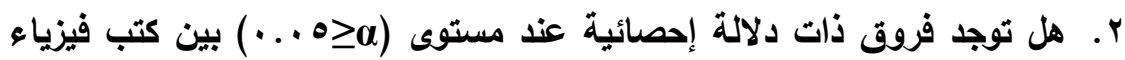

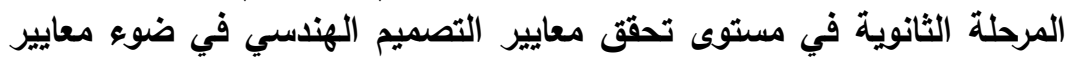

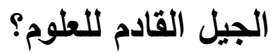

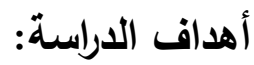

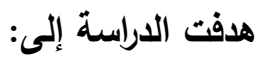

1. الكثف عن مستوى تحقق معايير التصميم الهندسي في ضوء معايير الجيل

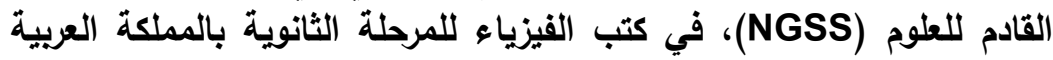
السعودية، وذلك حسب الأبعاد التالية: الممارسات العلبية العلمية والهندسية، والأفكار الرئيسة، والمفاهيم الشاملة.

رصد الفروق بين كتب الفيزياء للمرحلة الثانوية بالمملكة العربية السعودية والمتمثئة

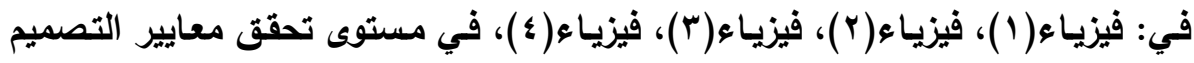
الهندسي في ضوء معايير الجيل القادم للعلوم. فياء. فياء

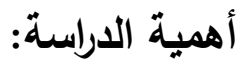

تمثلت أهمية الدراسة في أنّها قـ تساعد معلمي ومشرفي ومخططي مناهج العلوم

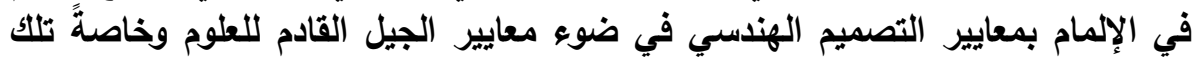

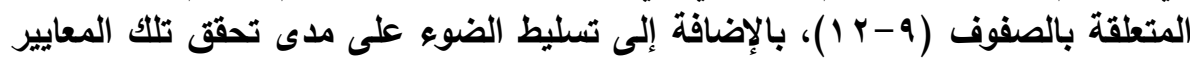




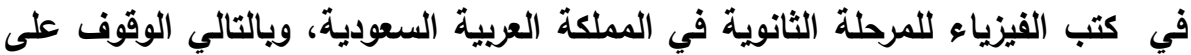

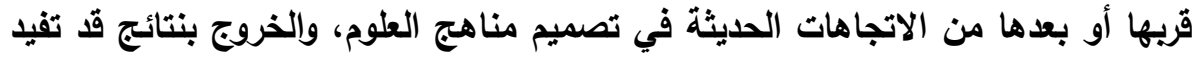

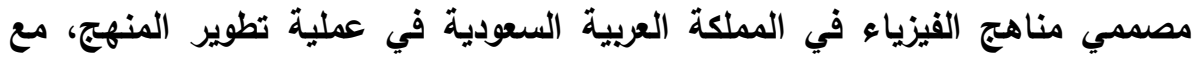

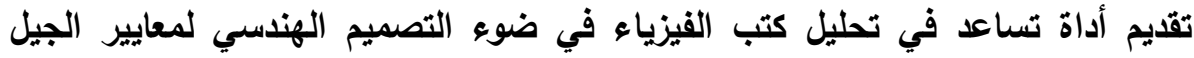
القادم للعلوم، والتي قد يستفيل منها الباحثون في بناء أدوات بحثية جليدة.

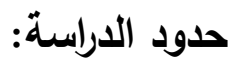

تم إجراء الاراسة الحالية في إطار حدود اقتصرت على أنثطة كتب الفيزياء

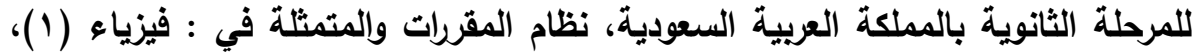

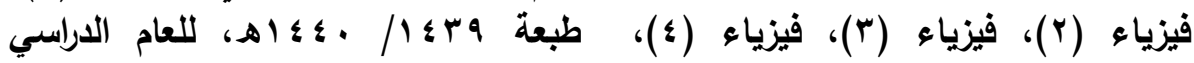

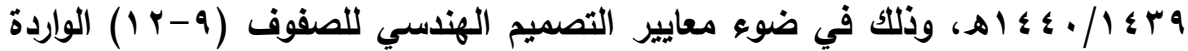

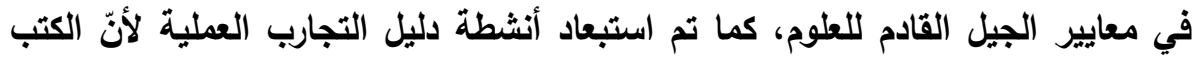

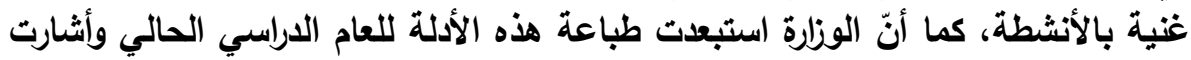

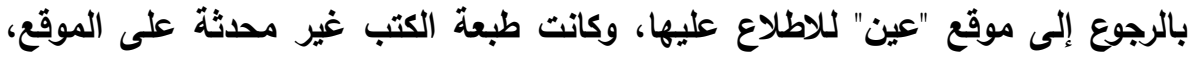

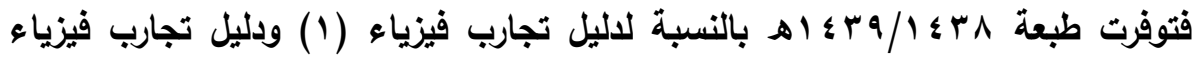

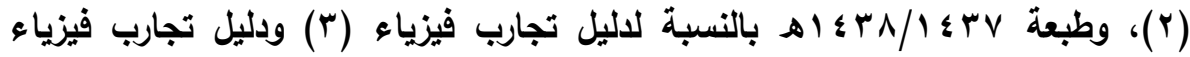

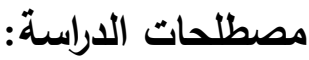

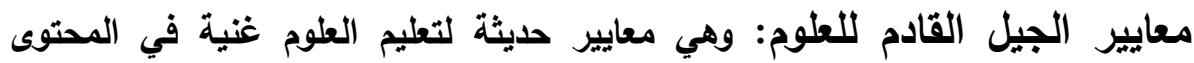

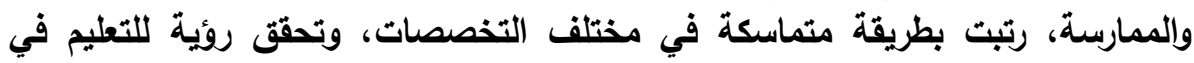

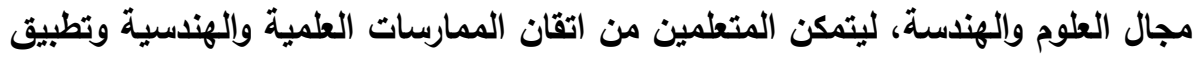

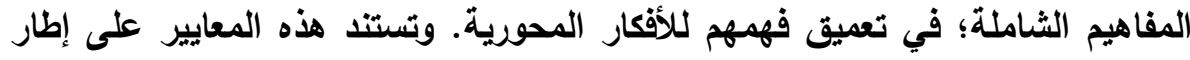
التربية العلمية (K-12) لتعليم العلوم، والذي تم إعداده من المجلس البحوث التوطني (NGSS, 2011) (NRC)

ويعرفها الباحثان إجرائيا بأنها: المعايير التي انظقت من مجلس البحوث الوطني

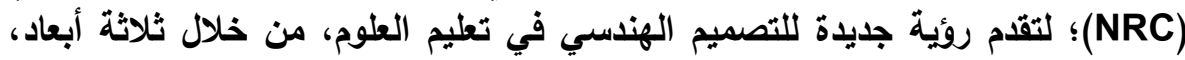

1. الممارسات العلمية والهنلسية: يقصد بالممارسات العلمية، الممارسات التي

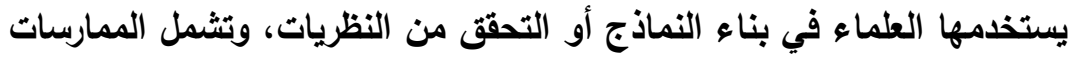
الهندية ما يستخدمه المهندسين في تصميم ويناء الأنظمة. $-7 \leqslant$ १ 


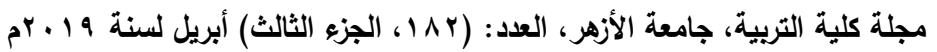

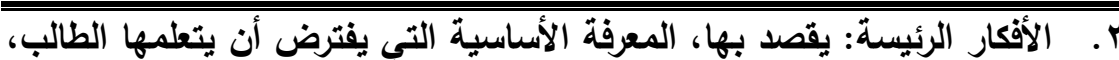

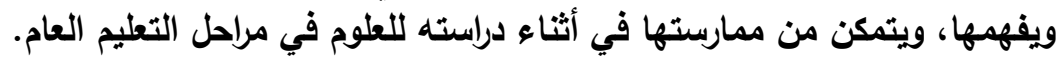

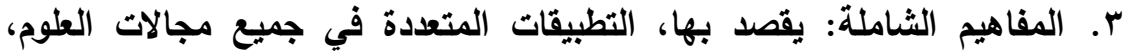

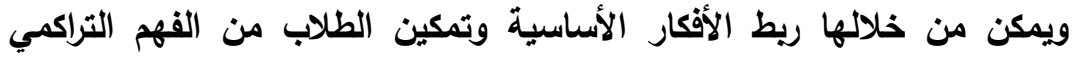

$$
\text { والمترابط. }
$$

التصميم الهندسي: ويقصد به الممارسات والأفكار هندسية الضرورية للمتعلمين،

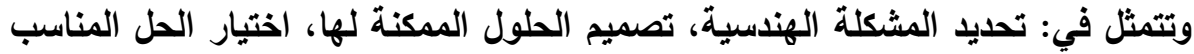

وتحسينه وتطويرها (NGSS Lead States, 2013)

ويعرفه الباحثان إجرائياً بأنه: ممارسة هندسية منهجية في كتب الفيزياء

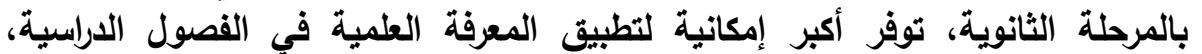

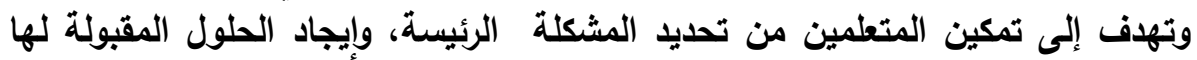
وتقييمها، ثم بناء النماذج الأولية واختبارها وتحسينها. الإطار النظري والدراسات السابقة.

لا يعد دمج الهندة في تعليم العلوم فكرة جديدة، حيث يرجع أصلها إلى "العلم

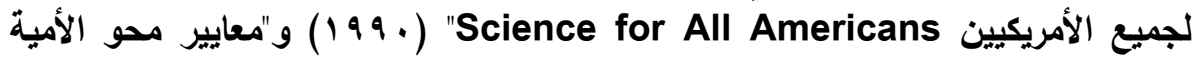

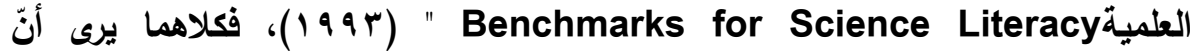

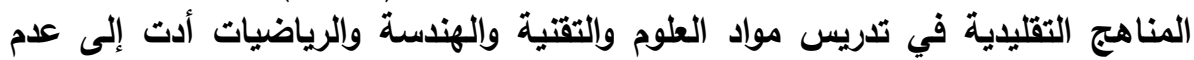
اهتمام المتعلمين بأنشطة تلك التخصصات، بالإضافة إلى كونها السبب وراء الألئة الأداء

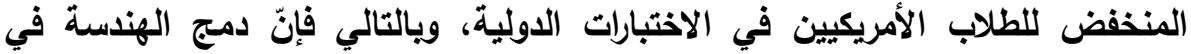
التعليم الرسمي يعد ضرورياً لاستيعاب تلكك التخصصات؛ لأن المعرفة العلمية يتم إنتاجها من خلال الهندسة، كما أنّ الاكتشافات العلمية الجديدة تغذيها التقتية التي تم إنشاؤها من

خلال التصميم الهندسي (Grubbs \& Greg, 2015).

ويعد تضمين الهندة كنظام في مناهج التعليم ما قبل الجامعي جديد نسبيًا،

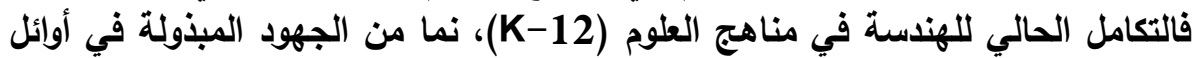

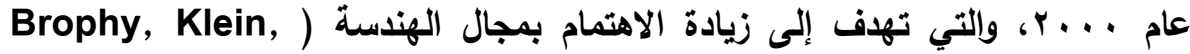
Portsmore, \& Rogers, 2008; National Academy of Engineering لمAE' and NRC, 2009

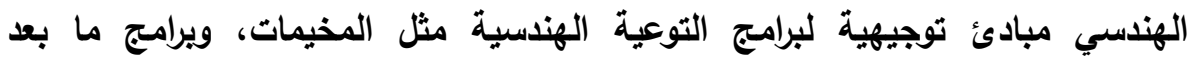

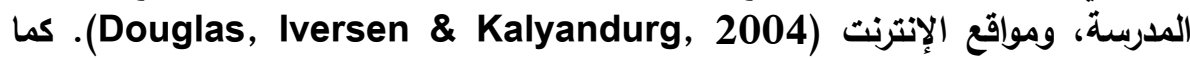
أثشار بروفي وزملاؤه (Brophy et al., 2008)، إلى أنّ الهندسة تحتاج أن تكون أكثر 
من نشاط خارج المنهج الداسي، وشجع على فكرة تضمين نظام الهندسة في المناهج

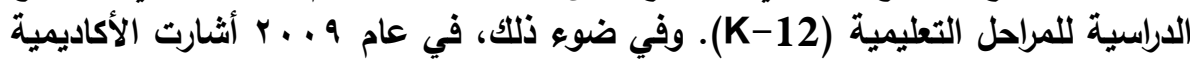

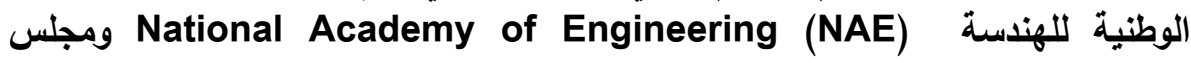

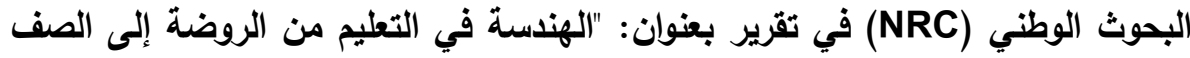

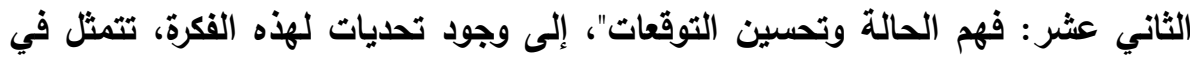

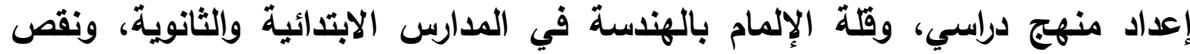

معلمي الهندسة المؤهلين (NAE \& NRC, 2009).

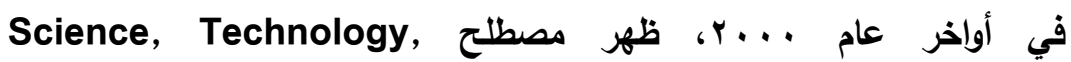
Engineering, and Mathematics (STEM)

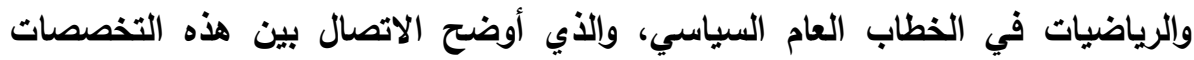

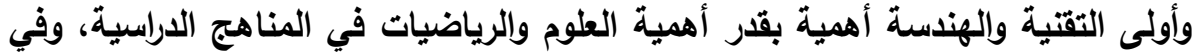

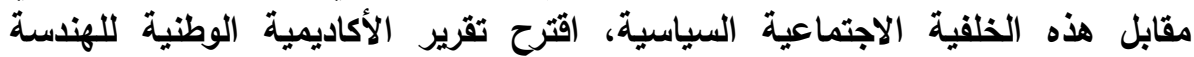

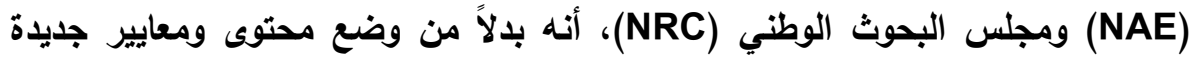

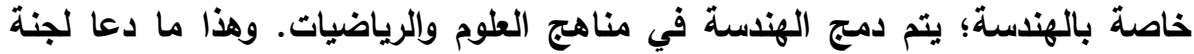

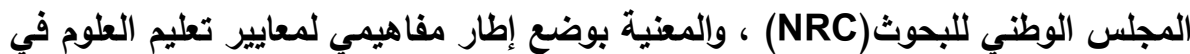

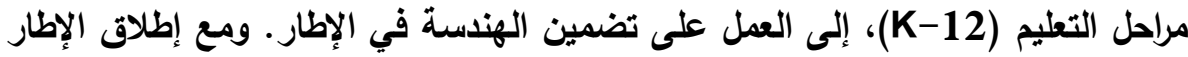

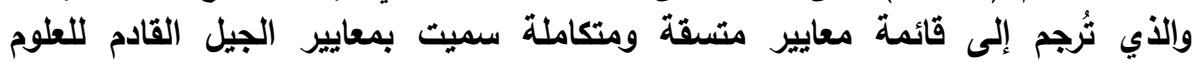

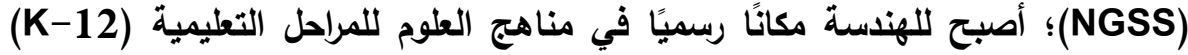

.(Kristin \& Tolbert, 2018)

ويتكون إطار عمل تطليم العلوم (K-12) ومعايير الجيل القادم للعلوم، من ثُلاثة

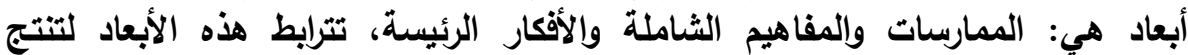

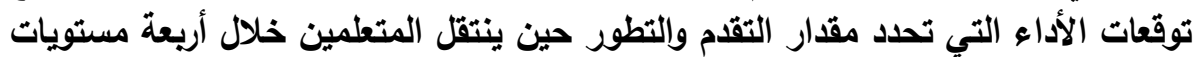

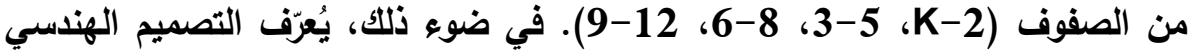

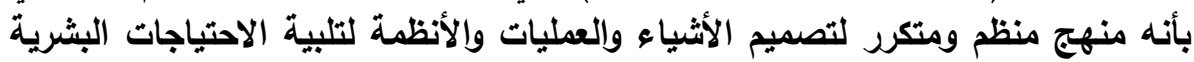

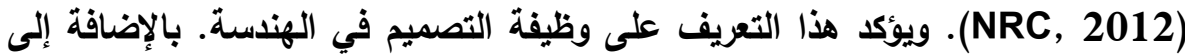

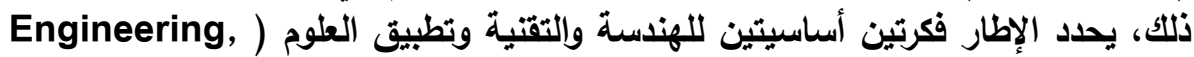
توئات أTechnology, Science "ETS"

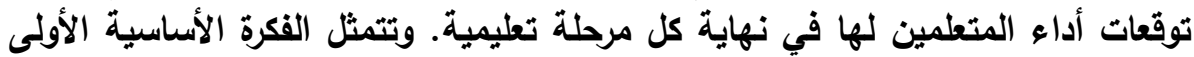

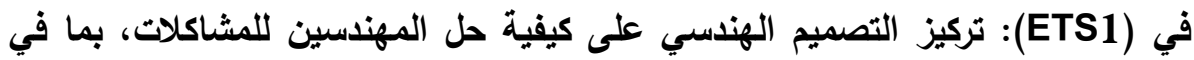

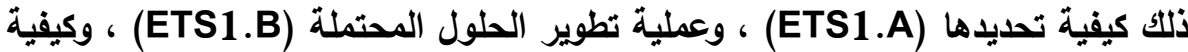
مقارنة الحلول المختلفة وتحسينها (ETS1.C). أما الفكرة الأساسية الثانية فتناقش الثالية 


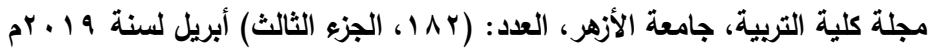

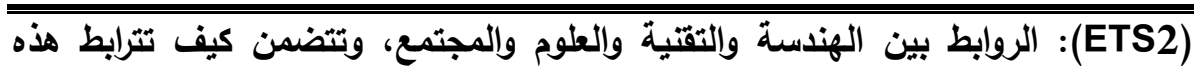

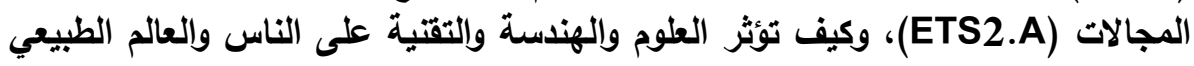
:ETS1 (ETS2.B)

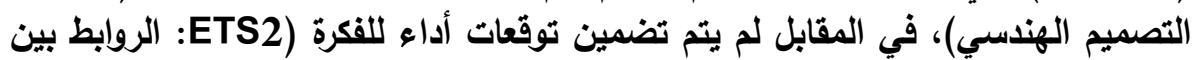

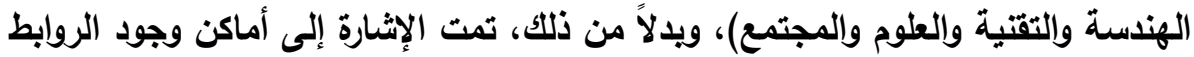

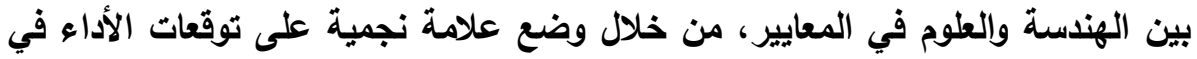

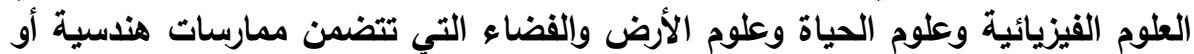
مفاهيم شاملة (Kristin \& Tolbert, 2018).

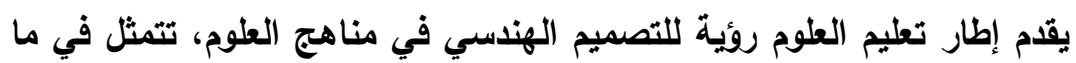

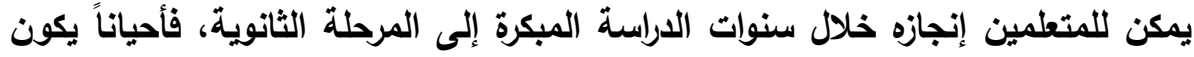

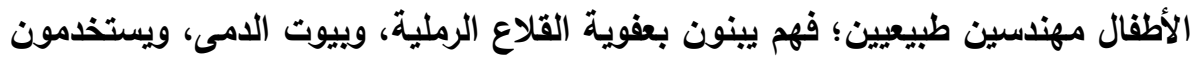

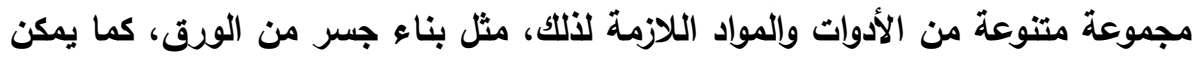

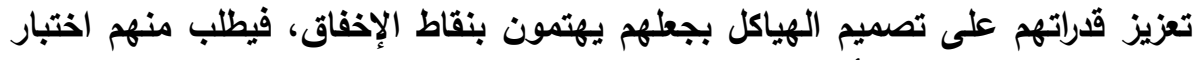

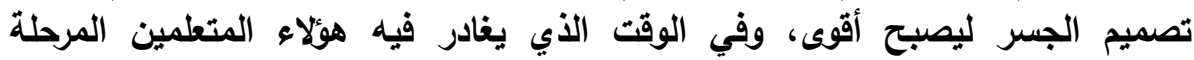

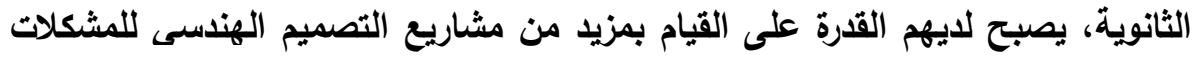

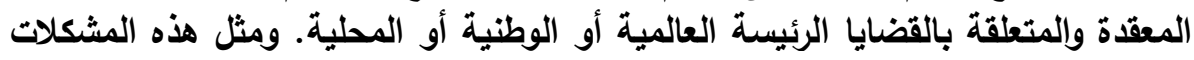

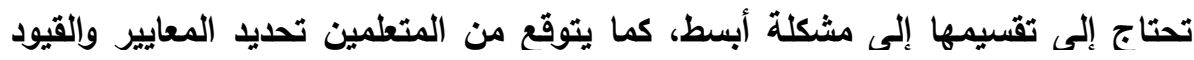

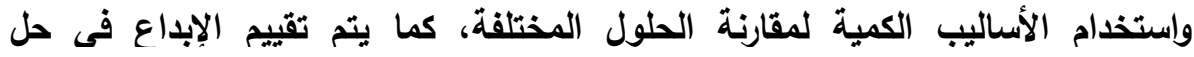

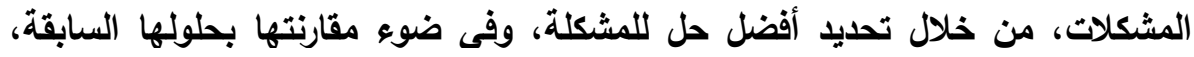

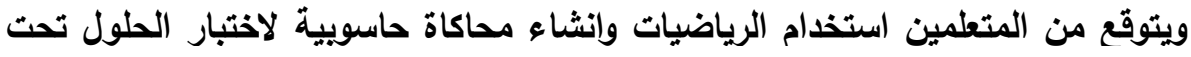

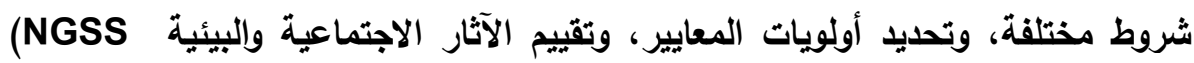

.Lead States, 2013)

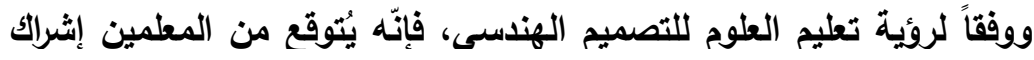

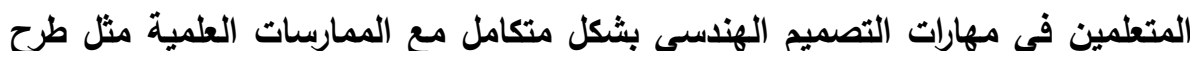

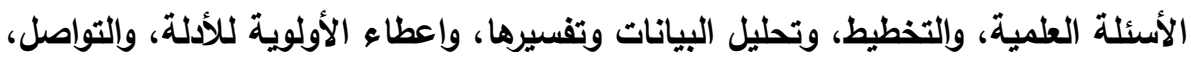

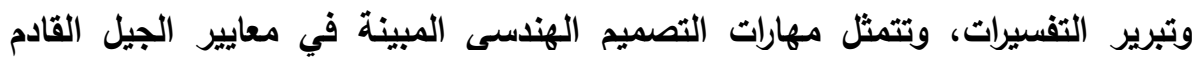
للعلوم في (NGSS Lead States, 2013; NRC, 2012)

1. تعريف وتحديد المشكلات الهندسية التي تمكنهم من فهم المشكلة، وتحديد

المعايير والقيود للحل الجيد للتصميم.

r. ت تطوير حلول التصميم التي تساعد المتعلمين في توليد الأفكار؛ لإثراء وتطوير حلول التصميم. 


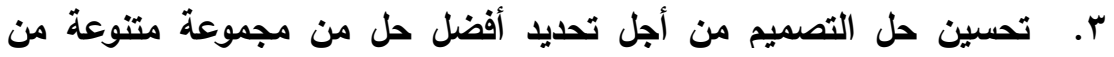
المعايير المتنافسة؛ وذلك من خلال إثرالك المتطمين في أنثطة التصميم

واختبارها.

؛. إجراء التتقيحات أو التكرار لتحسين حلول التصميم.

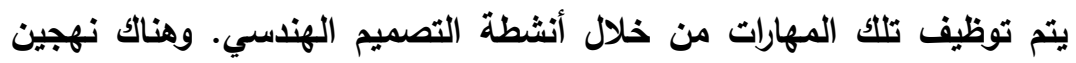

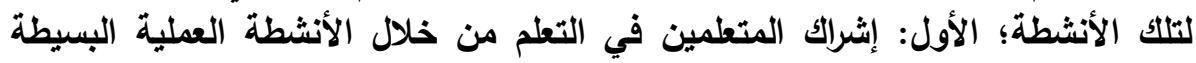

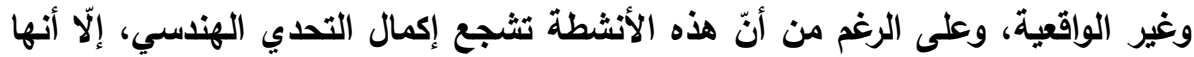

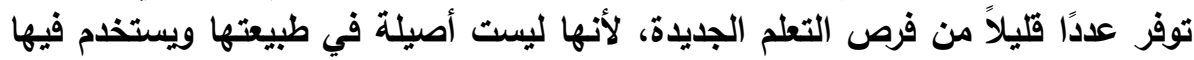

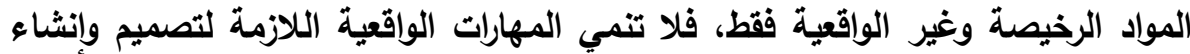

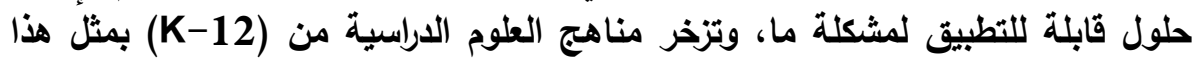

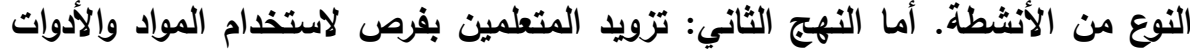

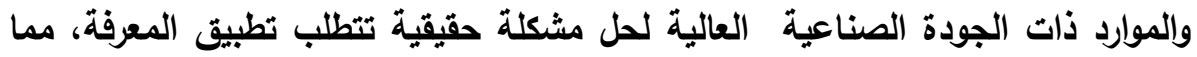

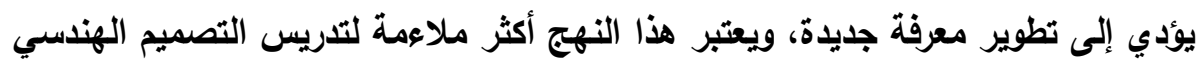

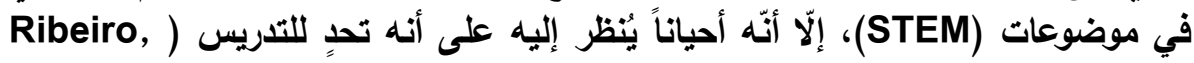

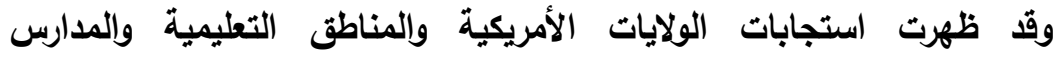

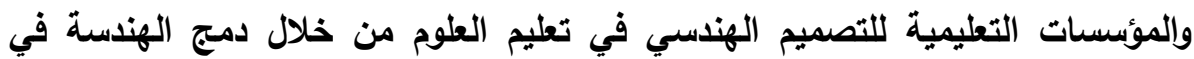

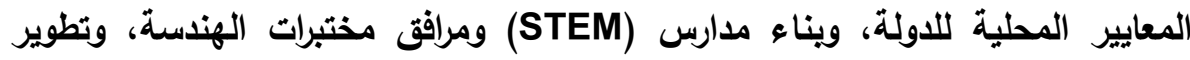

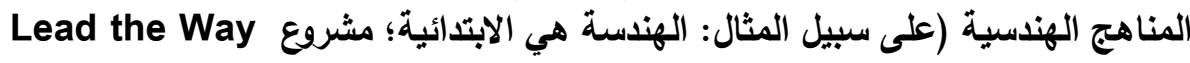

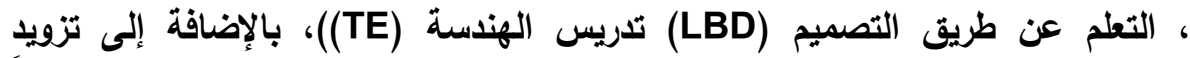

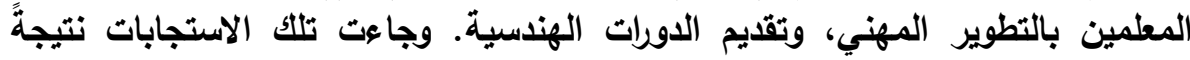
للحجج الثائعة لامج التصميم الهندسي في المناهج الدارينة

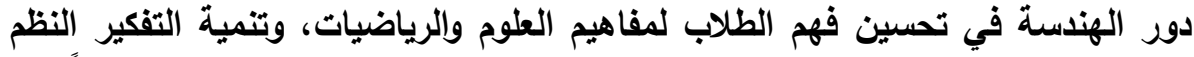

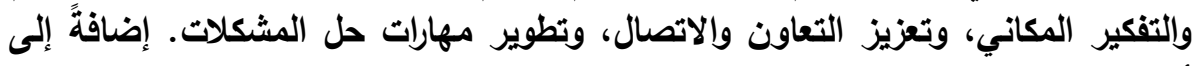

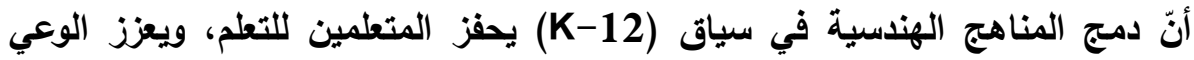

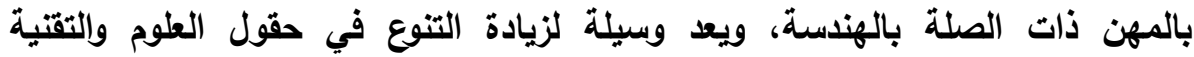

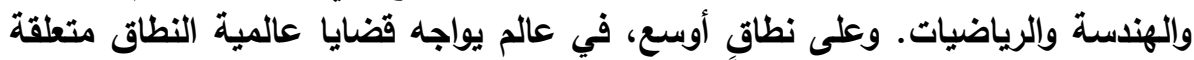

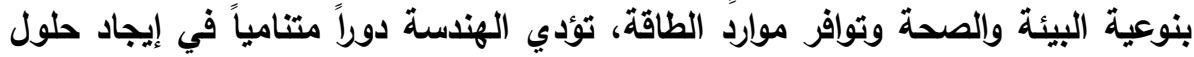

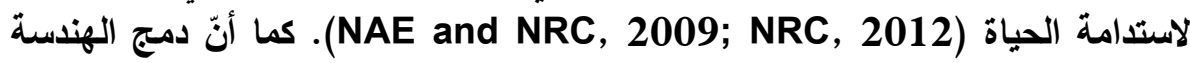
في المناهج الدراسية (K-12) يؤهل المتعلمين لمعالجة هذه القضايا في المستقبل، 


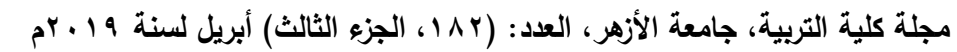

وبالتالى بناء مجتمع أفضل تعليماً قادراً على تلبية احتياجات القرن الواحد والعشرين

.(NGSS Lead States, 2013)

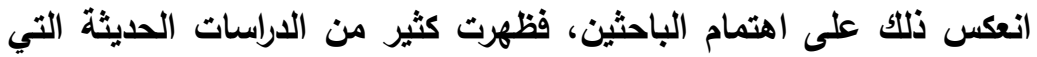

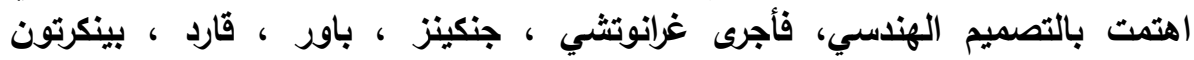

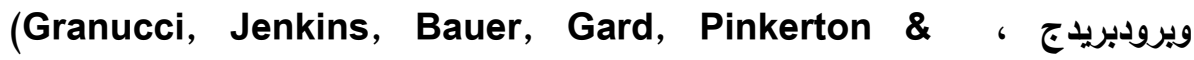
دراسة أثر استخدام مواد العلوم والهندسة كوسيلة تعليمية في

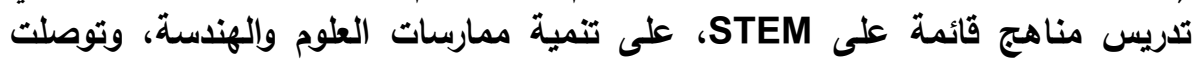

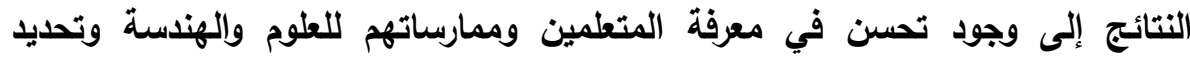
أهدافهم المهنية، كما زاد رضا المعلمين وثقتهه في تدريس مفاهيم العلوم والهندسة.

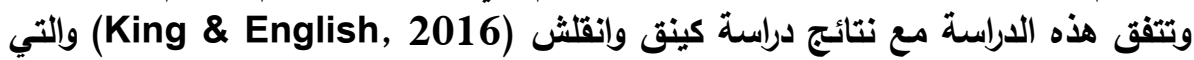

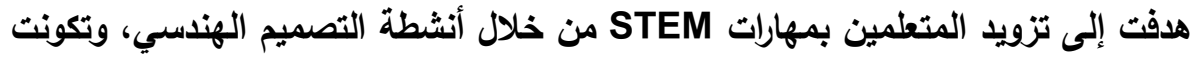

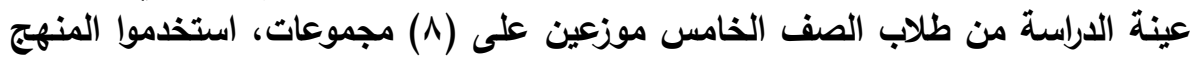

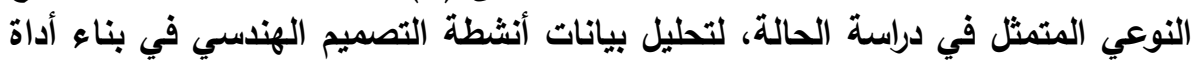

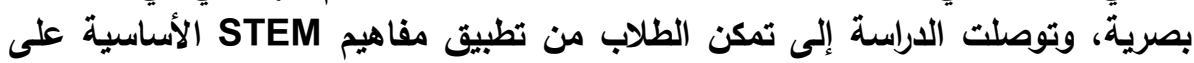
بناء النموذج، كما أنّ نموذج التصميم الهندسي كان مفيداً في هيكلة مراحل التصميم والبناء وإعادة التصميم.

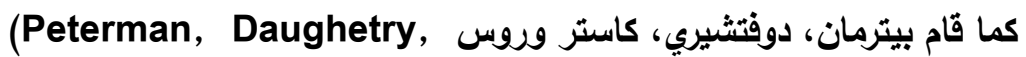
بتحديد الممارسات الهندية في مجال التعليم الهندسي من

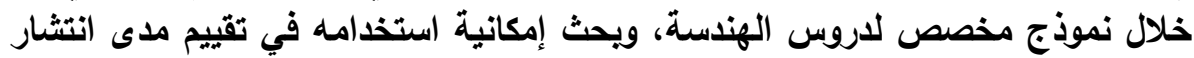

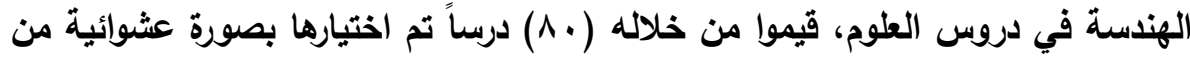

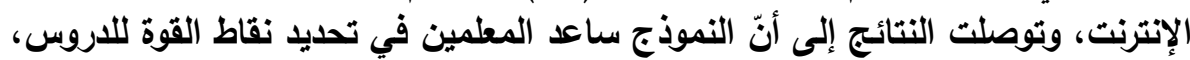

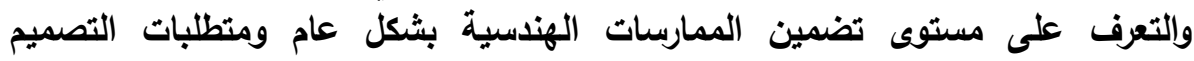
الهندسي في معايير الجيل القادم للعلوم بشكل خاص.

من زاوية أخرى، اهتمت دراسة مينق، ويتوورث، جونكزي، نيفي وويلر (Meang, Whiteorth, Gonczi, Navy \& Wheeler, 2017) معلمي علوم المرحلة الابتائية لمبادئ التصميم الهندسي (ED) في تدريسهم للعلوم بعد

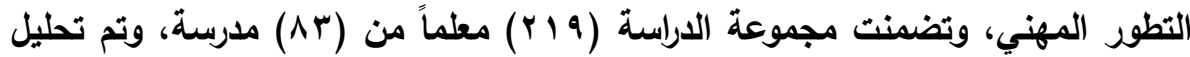

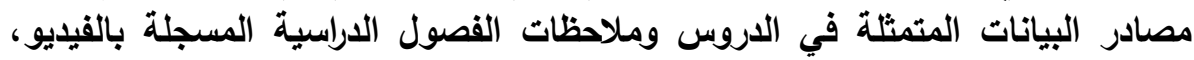

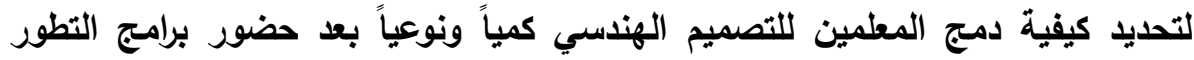

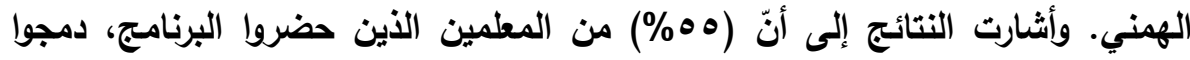
التصميم الهندسي وأجرى طلابهم البحوث وإختبروا التصاميم الأولية. 
وتتفق هذه الدراسة مع نتائج دراسة بوزدورفر (Boesdorfer, 2017)

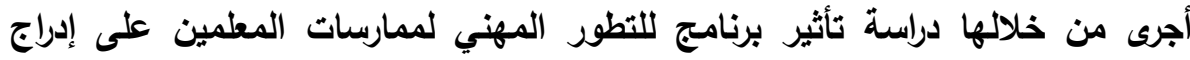

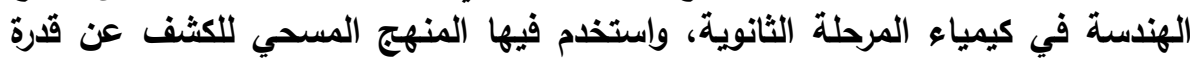

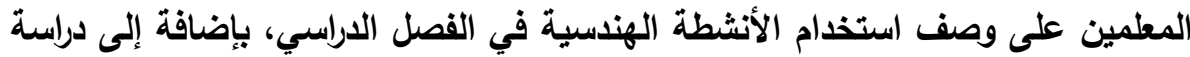

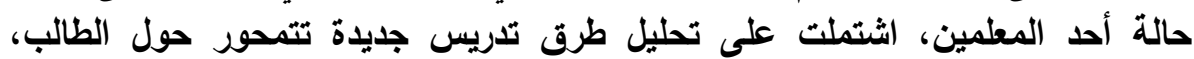

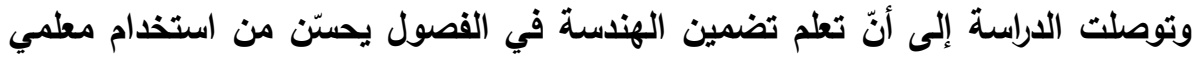
علوم المرحلة الثانوية للممارسات الهندسية المتححورة حول المتطلم.

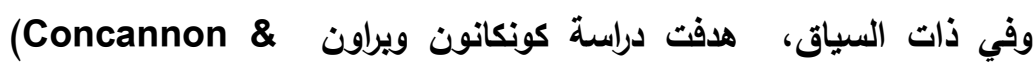
Brown, 2017)

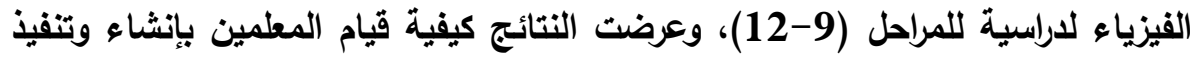

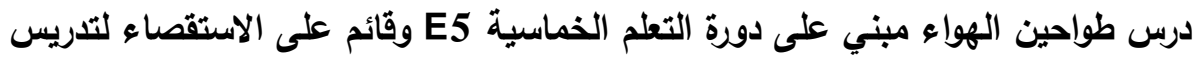

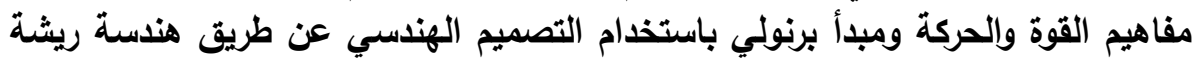
الطاحونة الهوائية.

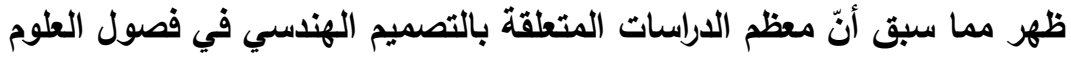

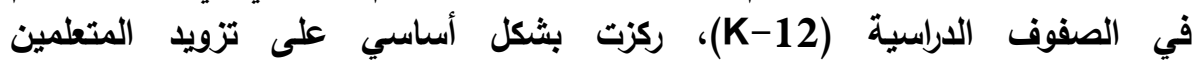

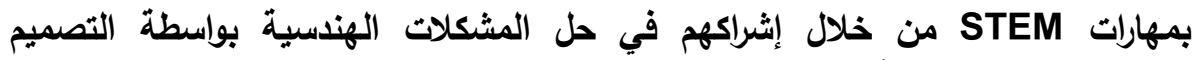

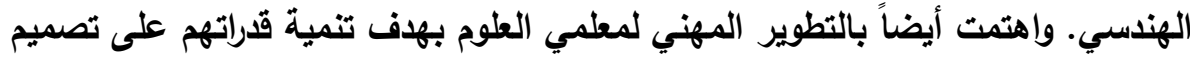

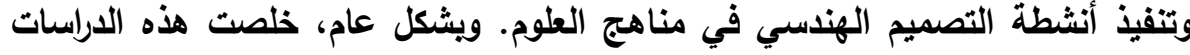

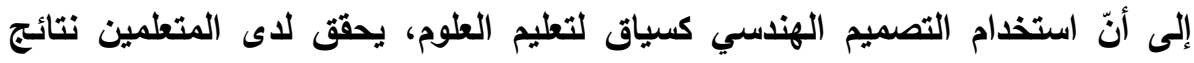

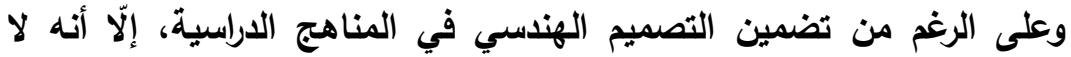

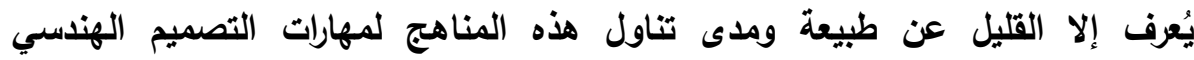

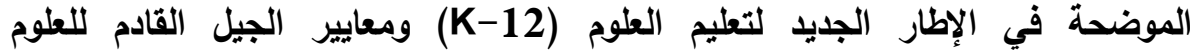
(NGSS)

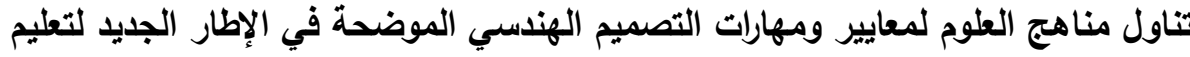

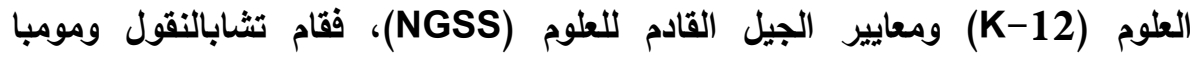
(Chabalengule \& Mumba, 2017)

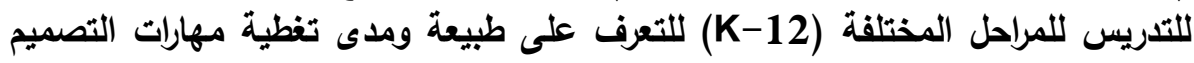

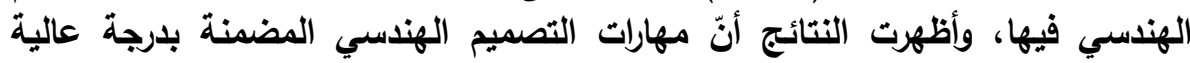
كانت: تطوير الحلول الممكنة والتصميم الفعلي للنماذج، أما المهارات التي تم تضمينها 
مجلة كلية التربية، جامعة الأزهر ، العدد: (r 1 1، الجزء الثالث) أبريل لسنة 9 ا ـام

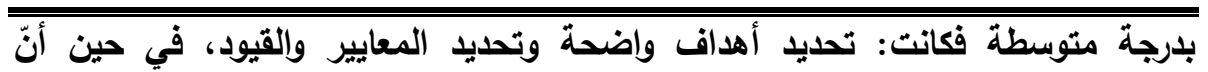

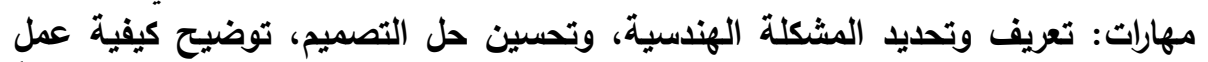

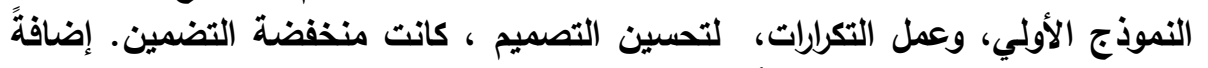

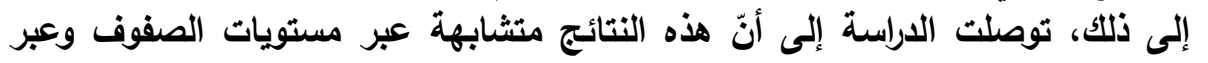

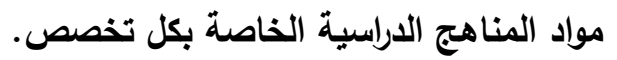

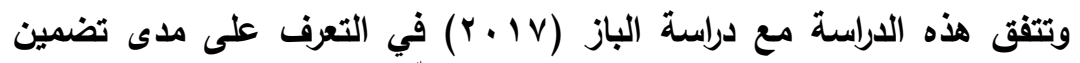

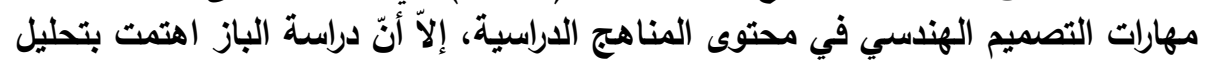

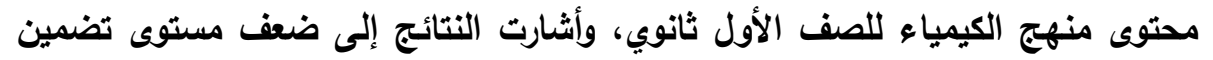

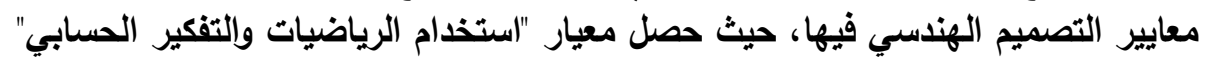

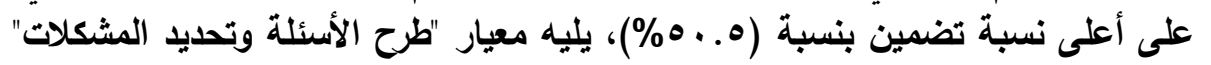

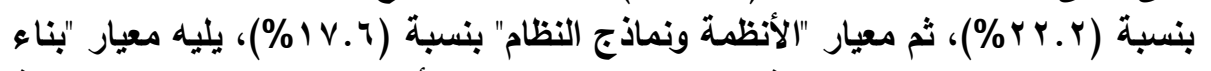

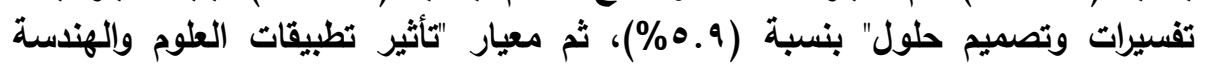

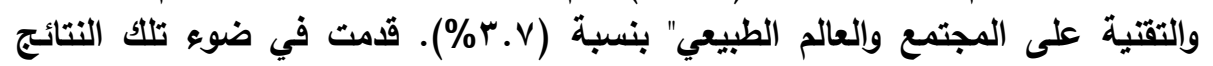

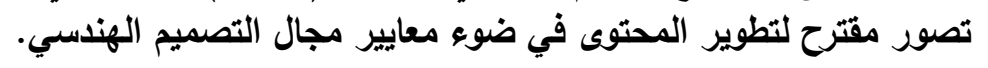

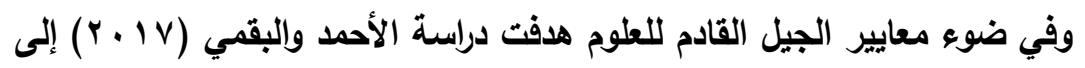

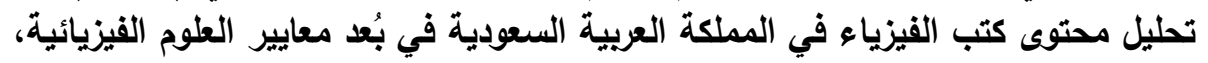

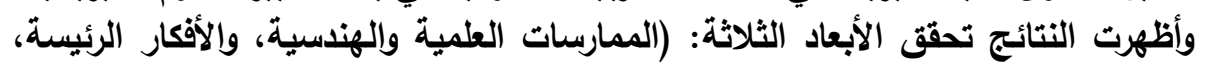

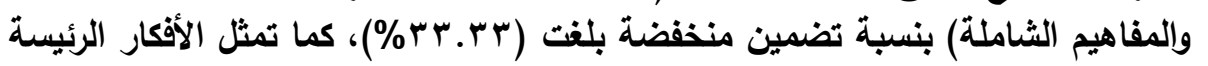

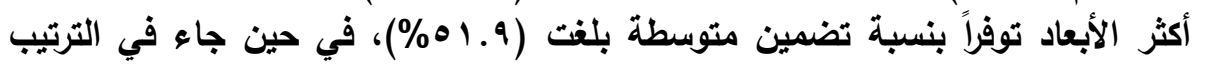

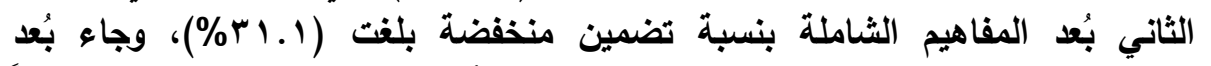

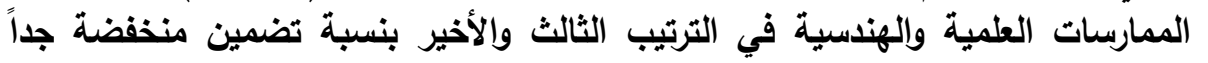

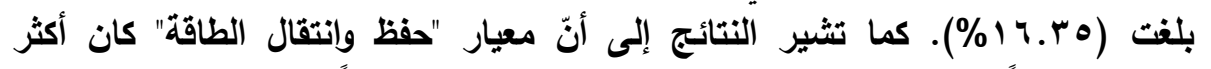

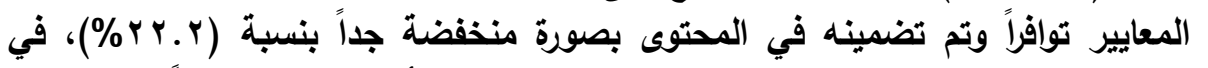

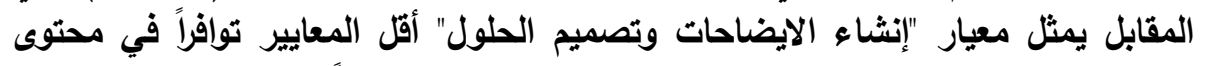

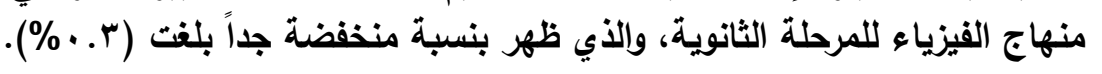

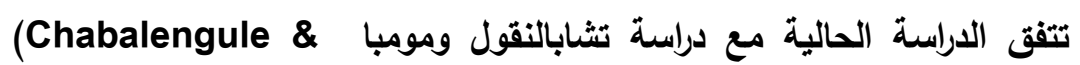

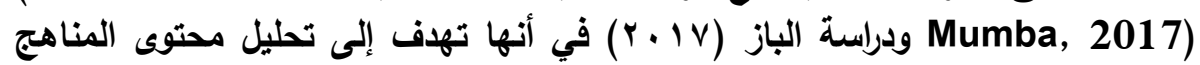

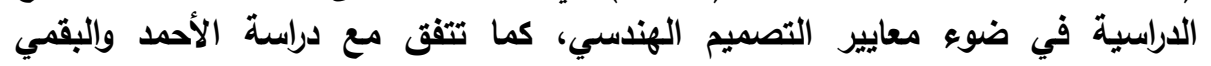
(r. lV)

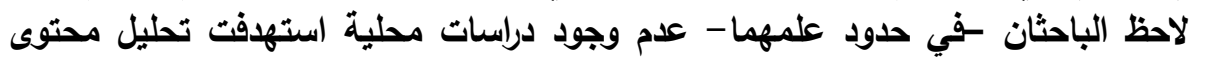

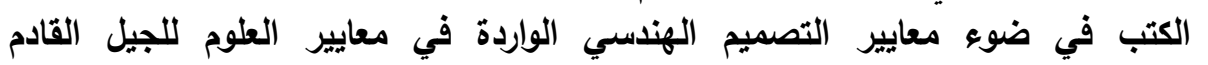


(NGSS)، مما يضفي أهمية وحاجة لإجراء مثل هذه الدراسات في المملكة العربية السعودية.

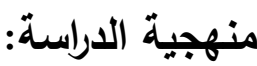

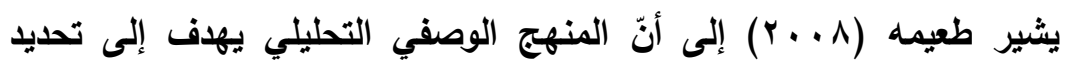
وإصدار حكم بشأن مدى توافق المناهج الدراسية مع معايير محددة، وينبغي توفرها فيه.

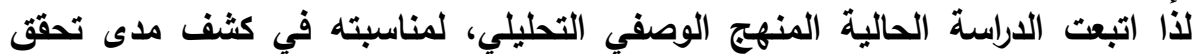

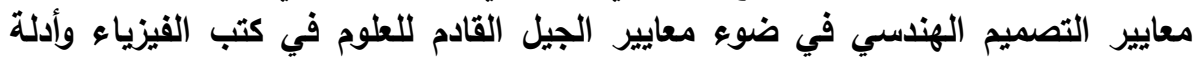
التجارب العملية للمرحلة الثانوية.

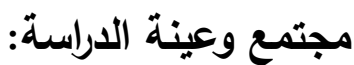

تكون مجتمع الدراسة من كتب الفيزياء المدرسية المقررة على طلبة المرحلة

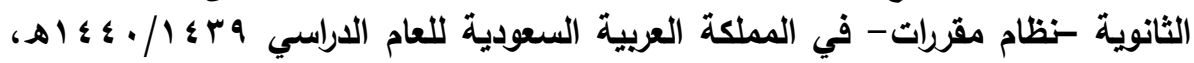

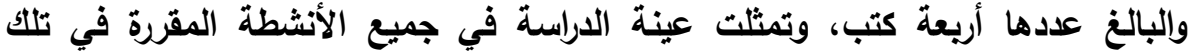

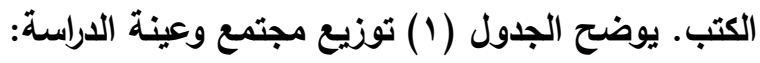

جدول (1): كتب الفيزياء والأنثطة المقررة على طلاب المرحلة الثانوية

\begin{tabular}{|c|c|c|c|}
\hline عدد الأنشطة في كتاب الطالب & عدد الفصول & الكتاب & م \\
\hline rA & $v$ & فيزياء1 & 1 \\
\hline$r r$ & $\Lambda$ & فيزياءr & $r$ \\
\hline rr & $\Lambda$ & فيزياءr & $r$ \\
\hline rA & $v$ & فيزياء ؛ & $\varepsilon$ \\
\hline ir. & r. & \multicolumn{2}{|c|}{ المجموع } \\
\hline
\end{tabular}

أداة الدراسةة: - ماسة

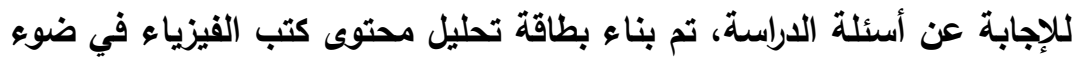

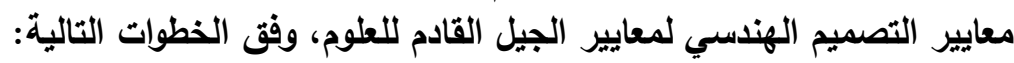

1. الحصول على قائمة معايير التصميم الهندسى الواردة في وثيقة معايير الجيل

القادم للعلوم (NGSS Lead States, 2013). 


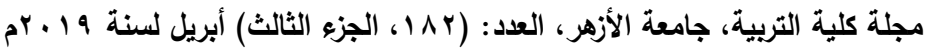

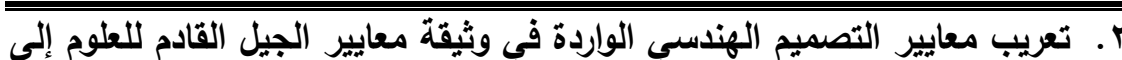

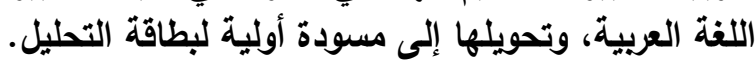
r. التحقق من الخصائص السيكومترية لبطاقة التحليل من الصدق والثة الثبات.

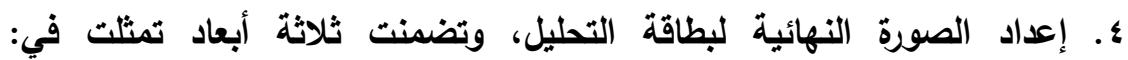

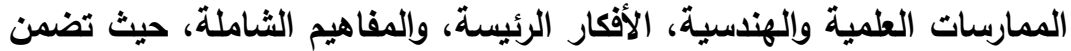

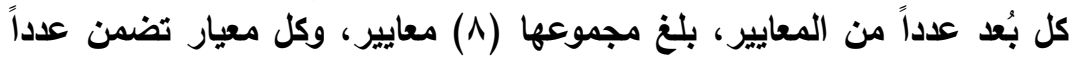

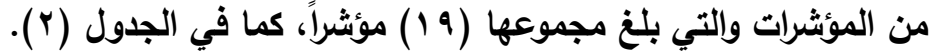
جدول (ץ): الأبعاد والمعايير والمؤثرات الفرعية للتصميم الهندسي

\begin{tabular}{|c|c|c|c|}
\hline نسبة المؤشر إلى & عدد المؤشرات & عدد المعاييير & الأبعاد \\
\hline$\% \diamond \vee . \wedge q$ & 11 & $r$ & الممارسات العلمية \\
\hline$\%$ \% 1.01 & 7 & $r$ & الأفكار الرئيسة \\
\hline$\% 1 . .0 \%$ & $r$ & $r$ & المفاهيم الثاملة \\
\hline$\% 1 \ldots$ & 19 & $\wedge$ & المجموع \\
\hline
\end{tabular}

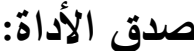

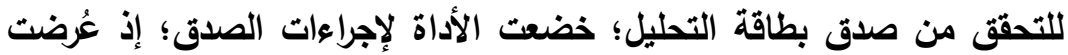

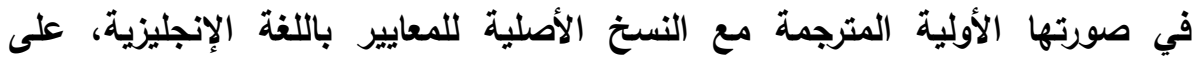
مجموعة من المحكمين المختصين في المناهج وطرق تلريس العلوم، لإلإبداء مرئياتهم

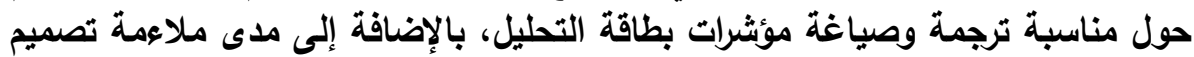

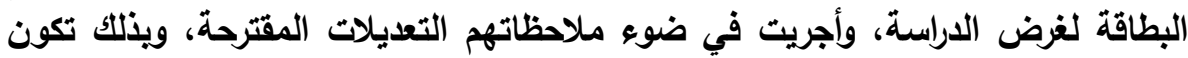

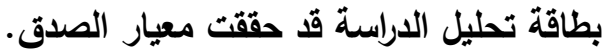

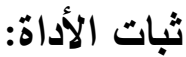

تم التحقق من ثبات الأداة بتحليل عينة استطلاعية من أنشطة كتب الفيزياء،

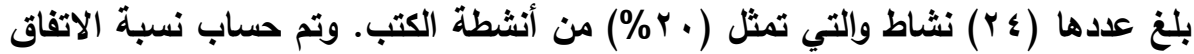

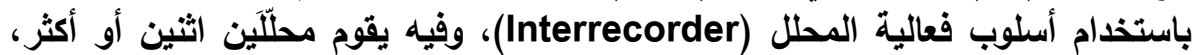

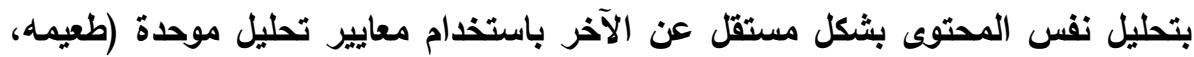

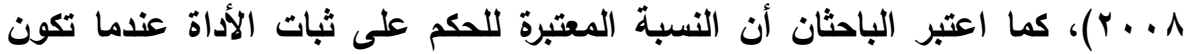


نسبة الاتفاق بين المحتلين مساوية أو أكبر من (ه^\%)، وتم استخام معادلة كوير (Cooper equation) نسبة مقبولة للثبات.

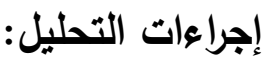

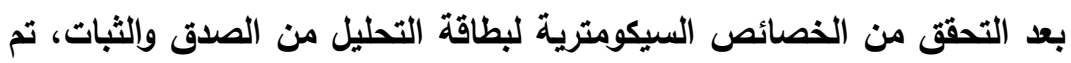
تحليل أنثطة كتب الفيزياء وفق منهجية منضبطة لتحقيق أدق النتائج، وجرت عملية النية التحليل وفق الخطوات التالية: التياء

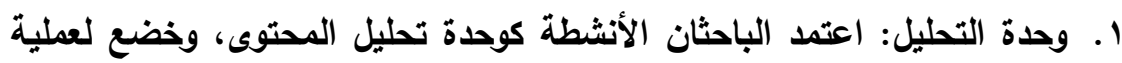

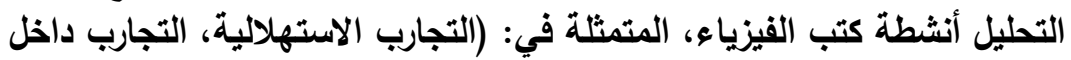

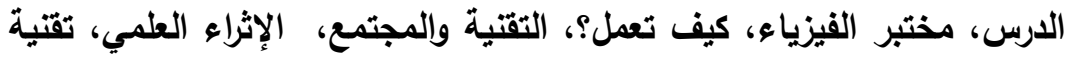
(المستقبل).

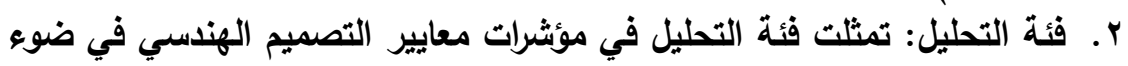

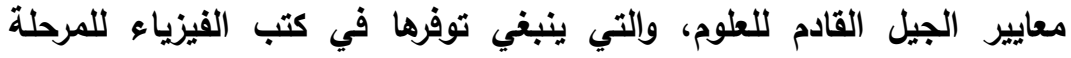

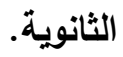

r. استخدام بطاقة تحليل واحدة لكل نثاط للكثف عن مدى تحقق معايير التصميم

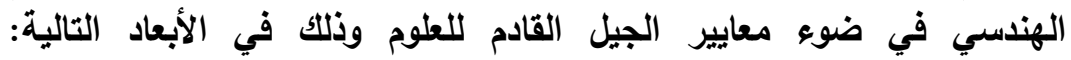

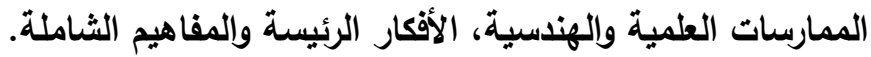

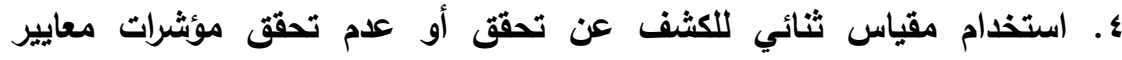

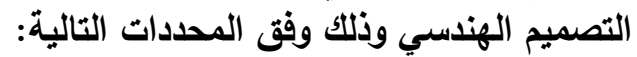
• متحقق، يعطى التقاير (1): عندما يتوفر المؤشر في النثاط بشكل

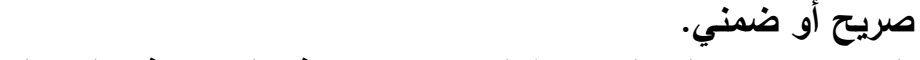
• غير متحققى، يعطى التقبير (·): عندما لا يتوفر المؤثشر في النشاط.

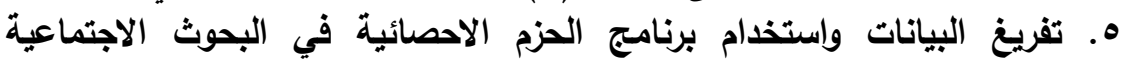
1 التحليلها واستخراج النتائج. 1. . تقير مستوى تحقق المعايير وفق النسب المئوية التالي:

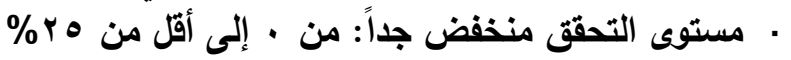

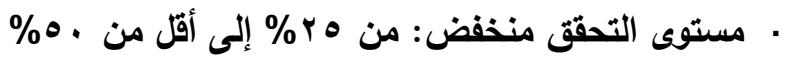

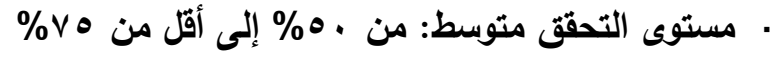

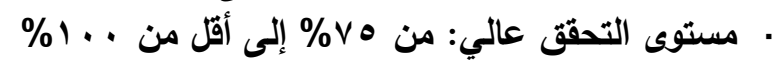




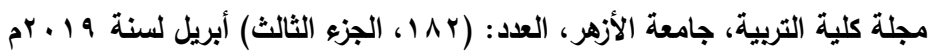

\section{المعالجة الإحصائية:}

في ضوء البحث استخدم الباحثان الأساليب الإحصائية التالية:

1. معادلة كوير (Cooper equation) لتقدير نسبة الاتفاق بين المحللين

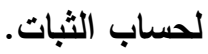

r. ب التكرارات والنسب المئوية.

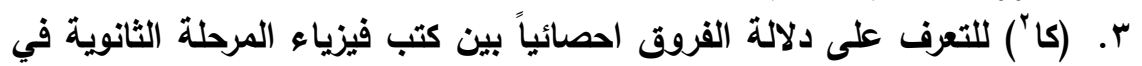

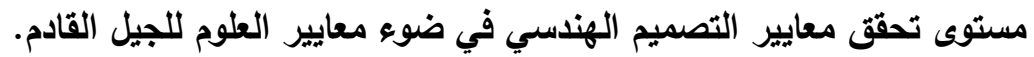

نتائج الدراسة:

نتائج ومناقشة السؤال الأول:

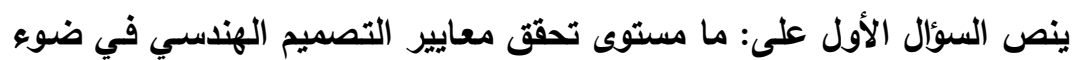

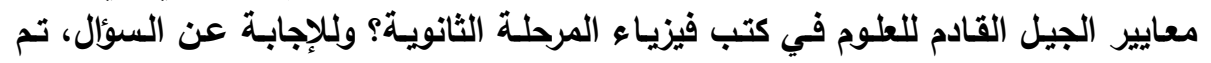

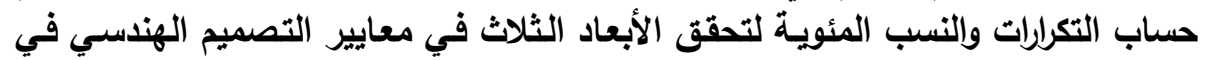

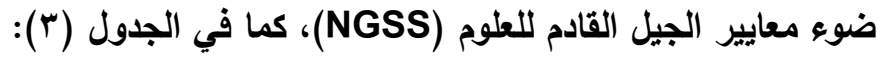
جدول (ץ): التكرارات والنسب المئوية للأبعاد الثلاثة في معايير التصميم الهندسي

\begin{tabular}{|c|c|c|c|c|c|}
\hline \multirow{2}{*}{ المجموع } & \multicolumn{3}{|c|}{ المعايير } & \multirow{2}{*}{$\begin{array}{l}ت \\
\%\end{array}$} & \multirow[b]{2}{*}{ الكتاب } \\
\hline & المفاهيم الشاملة & الأفكار الرئيسة & الممارسات العلمية & & \\
\hline$V \leq 0$ & $1 \cdot r$ & rrr & $\varepsilon Y 1$ & ت & \multirow{2}{*}{ المجموع } \\
\hline \%rr.r & $\%$ Ir.v & $\%$ \% $9 . \wedge$ & $\% 07.0$ & $\%$ & \\
\hline
\end{tabular}

يتضح من الجدول (r) أنّ تحقق معايير التصميم الهندسي في الأبعاد الثلاث

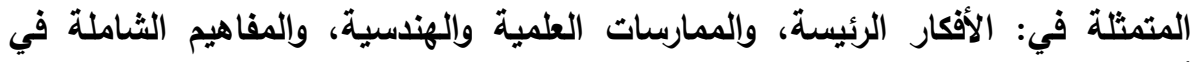

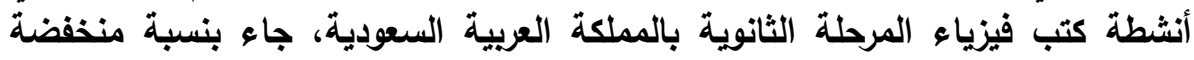

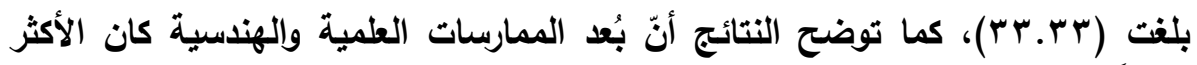

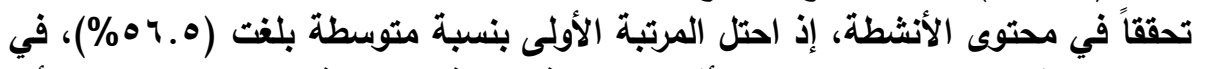

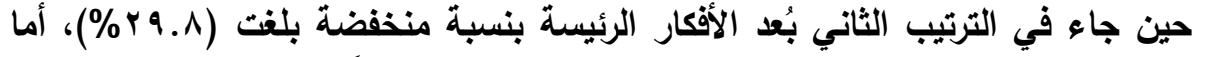

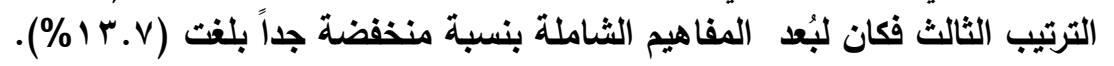


ويعزو الباحثان هذه النتيجة إلى تباين طبيعة أنشطة كتب الفيزياء. وللتعرف

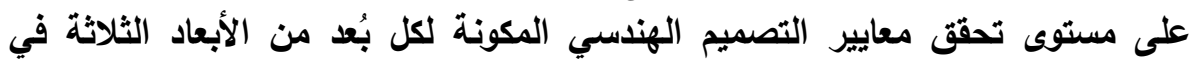

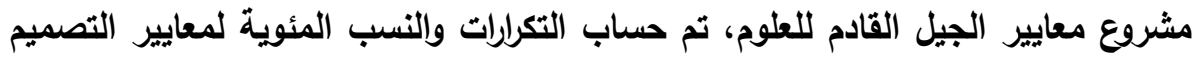
الهندسي في كل بُعد كما يلي:

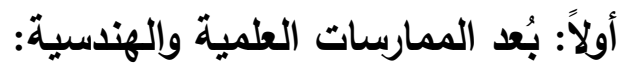
يتضح من الجدول (؛)، أنّ معايير التصميم الهندسي في بعد المثارسات

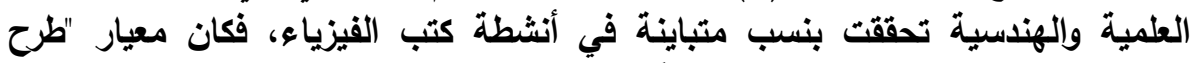

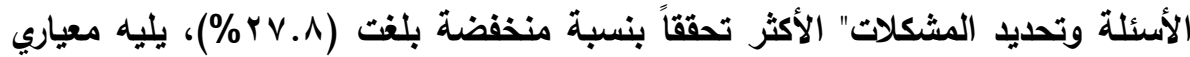

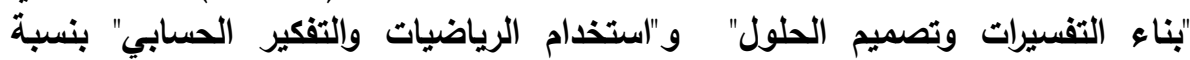

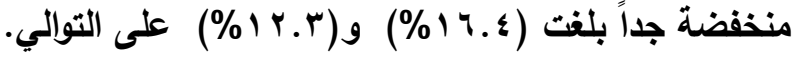
جدول (؛): التكرارات والنسب المئوية لمعايير التصميم الهندسي في بُعد الممارسات العلمية والهندسية.

\begin{tabular}{|c|c|c|c|c|}
\hline \multicolumn{3}{|c|}{ المعاييز } & \multirow{2}{*}{$\begin{array}{l}ت \\
\%\end{array}$} & \multirow[b]{2}{*}{ الكتاب } \\
\hline بتاء التفسيرات & والتفكير الحاسوبي الرياضيات & وتحديد المشكلات الأسئلة & & \\
\hline ro & $r V$ & $\leqslant r$ & ت & \multirow{2}{*}{ فيزياء (1) } \\
\hline$\%$ \%.z & $\% r .7$ & $\% 0.7$ & $\%$ & \\
\hline rr & rA & or & $\ddot{H}$ & \multirow{2}{*}{ فيزياء (r) } \\
\hline$\% \leq . \varepsilon$ & $\% r . \wedge$ & $\% \vee .1$ & $\%$ & \\
\hline$r r$ & YI & 7. & $\ddot{ت}$ & \multirow{2}{*}{ فيزياء (r) } \\
\hline$\% \varepsilon . \varepsilon$ & $\%$ \%.A & $\% \wedge$ & $\%$ & \\
\hline$r_{1}$ & 17 & Or & 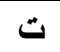 & \multirow{2}{*}{ فيزياء (ع) } \\
\hline$\% \leq . Y$ & $\%$ r. 1 & $\% \mathrm{~V}$ & $\%$ & \\
\hline IrY & $9 r$ & $r \cdot V$ & $\ddot{H}$ & \multirow{2}{*}{ المجموع } \\
\hline$\% 17.4$ & $\%$ \%।Y.r & $\%$ YV.A & $\%$ & \\
\hline
\end{tabular}

$-707-$ 


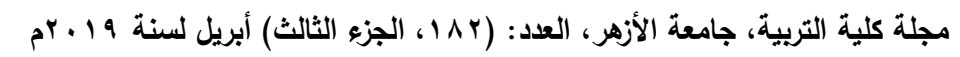

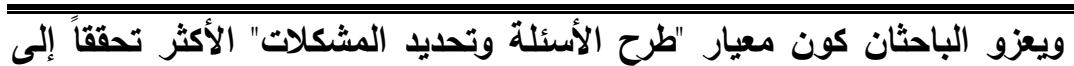

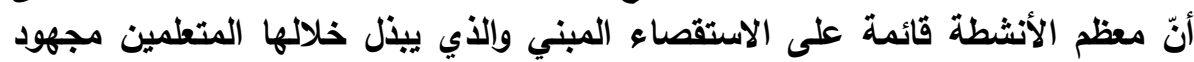

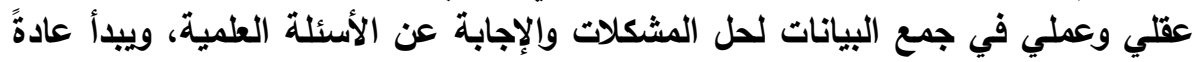

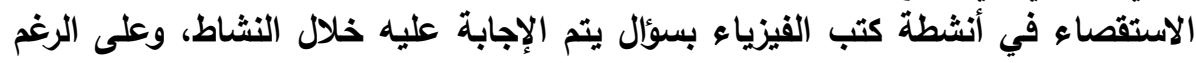

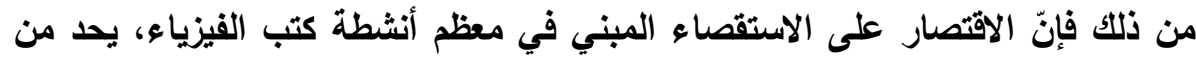

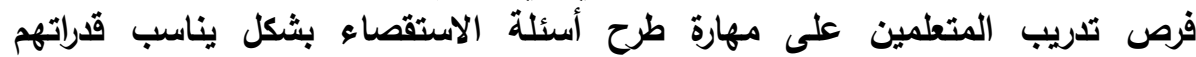
ويساعدهم على التعلم الأتي. تُوبن

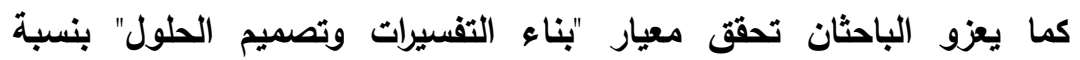

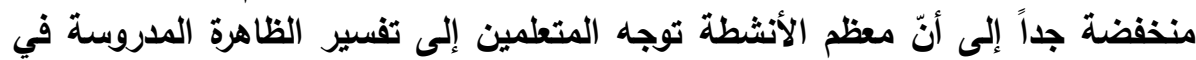

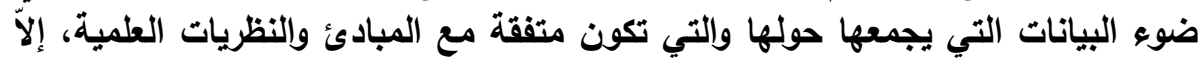

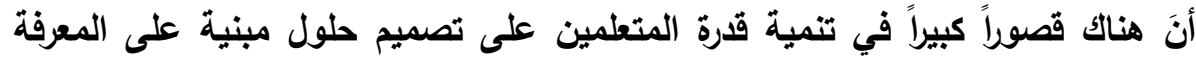

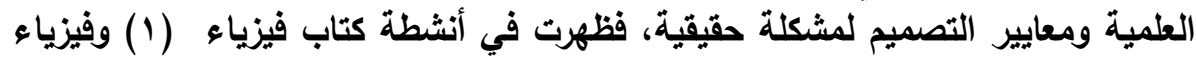

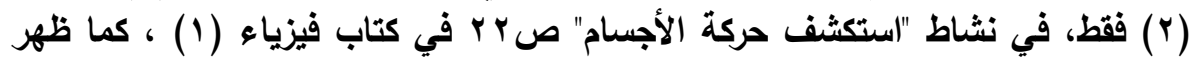

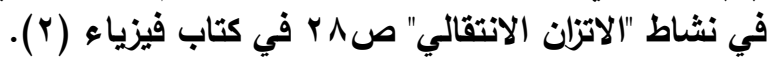

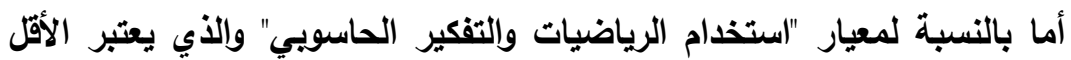

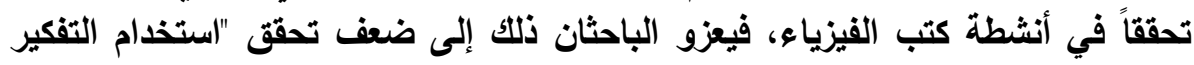

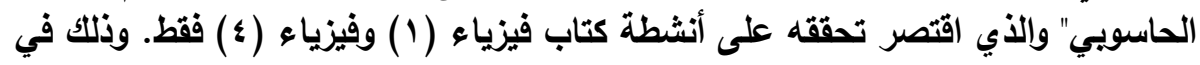

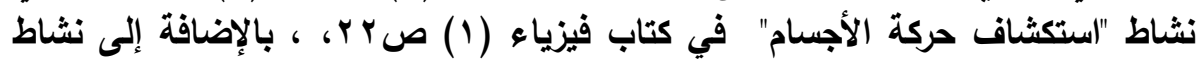

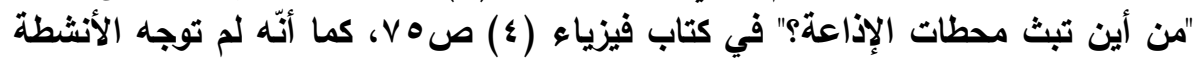

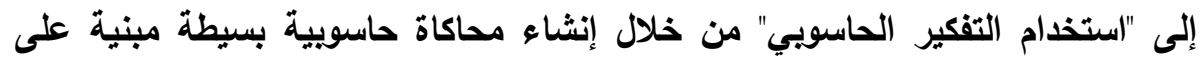

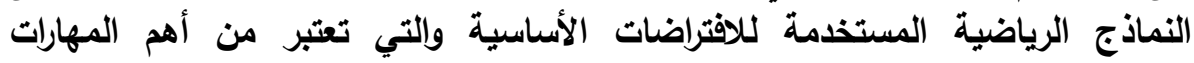

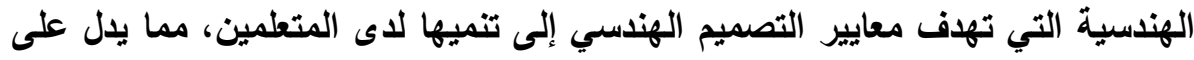

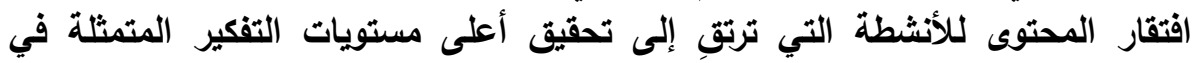

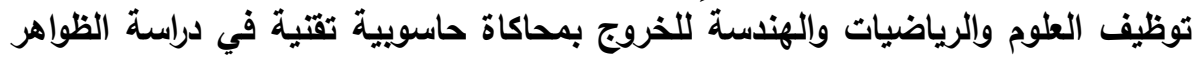

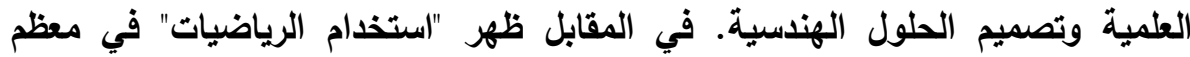

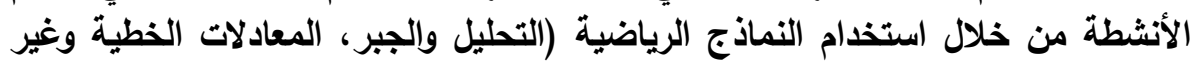
الخطية، الرسوم البيانية، الجداول).

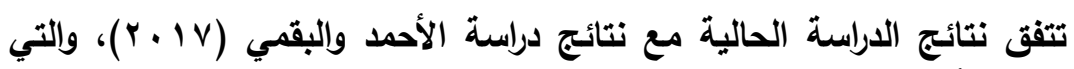

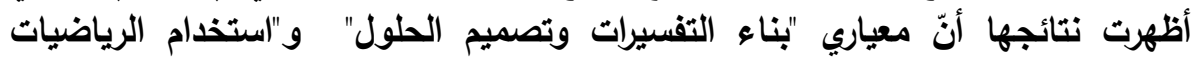

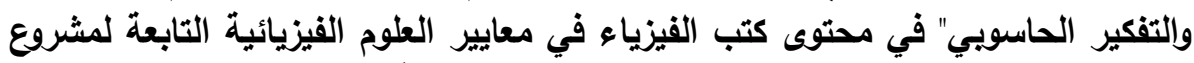

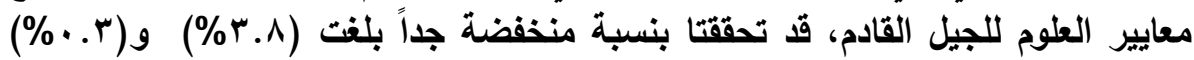




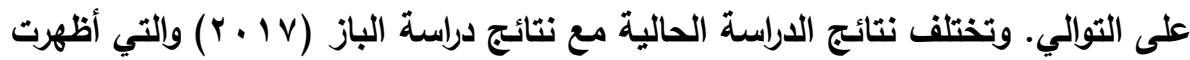

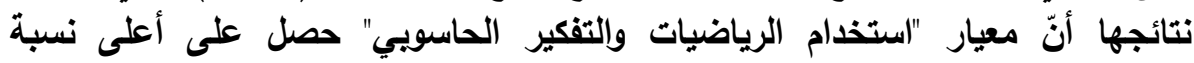

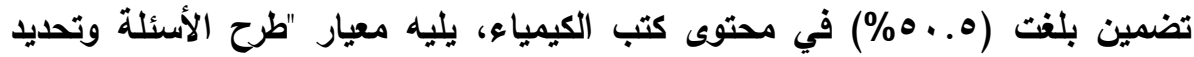

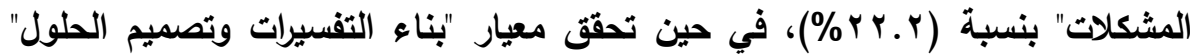

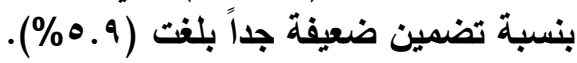
ثانياً: بعد الأفكار الرئيسة:

يتضح من الجدول (0)، أنّ معايير التصميم الهندسي في بعد الأفكار الرئيسة تحققت بنسب منخفضة جداً في أنشطة كتب الفيزياء، فتحقى معيد معيار "تعريف وتحديد

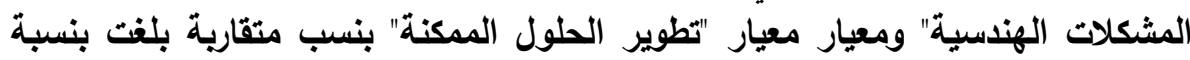

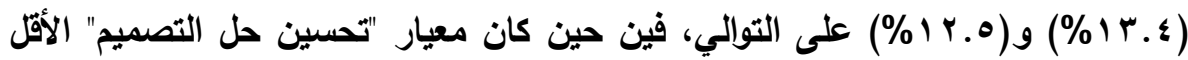

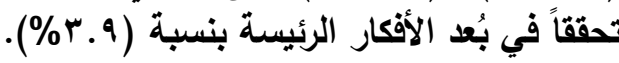
جدول (•): التكرارات والنسب المئوية لمعايير التصميم الهندسي في بُعد الأفكار الرئيسة.

\begin{tabular}{|c|c|c|c|c|}
\hline \multicolumn{3}{|c|}{ المعايير } & \multirow{2}{*}{$\begin{array}{l}ت \\
\%\end{array}$} & \multirow[b]{2}{*}{ الكتاب } \\
\hline تصسين حل & تطوير الحلول & المشريف وتحديد الهندسية & & \\
\hline$\varepsilon$ & 10 & 11 & $ت$ & \multirow{2}{*}{ فيزياء (1) } \\
\hline$\% . .0$ & $\%$ \%.l & $\%$ Y. \{ & $\%$ & \\
\hline$\Lambda$ & $r$. & $r r$ & ت & \multirow{2}{*}{ فيزياء (r) } \\
\hline$\% 1.1$ & $\%$ \%. & $\%$ \%.l & $\%$ & \\
\hline 11 & rr & rr & 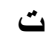 & \multirow{2}{*}{ فيزياء (r) } \\
\hline$\% 1.0$ & $\% \varepsilon . r$ & $\%$ \% . & $\%$ & \\
\hline 7 & Y & rq & ت & \multirow{2}{*}{ فيزياء (ع ) } \\
\hline$\% . . \wedge$ & $\%$ \%. \& & $\%$ r.o & $\%$ & \\
\hline rq & 94 & $1 \ldots$ & ت & \multirow{2}{*}{ المجموع } \\
\hline$\%$ r.q & $\% \mid$ Y.० & \%।r. & $\%$ & \\
\hline
\end{tabular}

ويعزو الباحثان هذه النتائج إلى أنّ مناهج الفيزياء الحالية مبنية على أساس معايير التربية العلمية والتي لا تهتم بشكل كبيز البن بمهارات تصميم وتحسين الحلول $-701-$ 
مجلة كلية التربية، جامعة الأزهر ، العدد: (r 1 1، الجزء الثالث) أبريل لسنة 9 ا بام

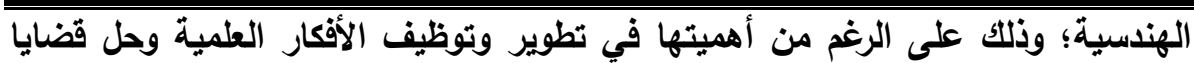

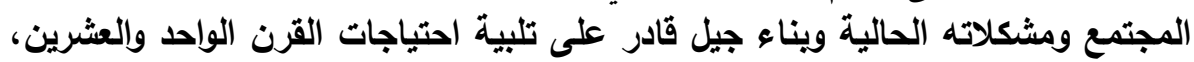

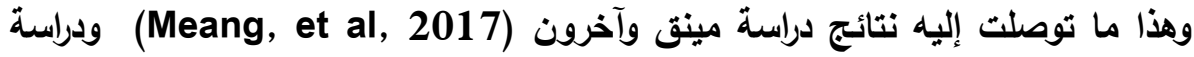

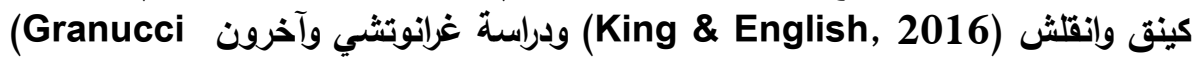

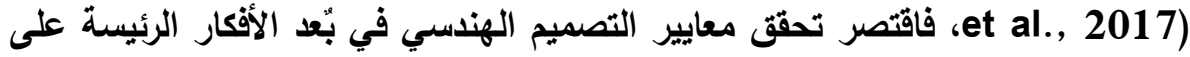

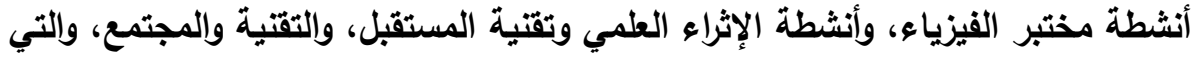

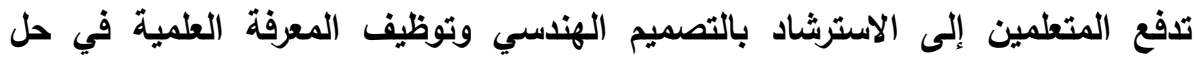

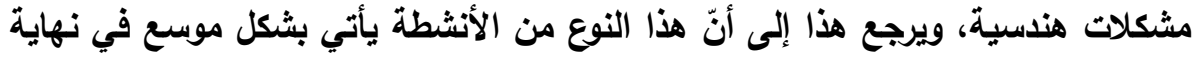

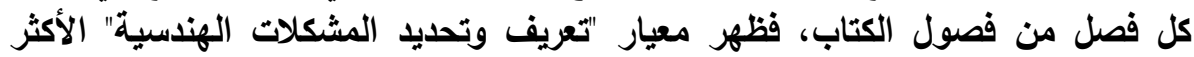

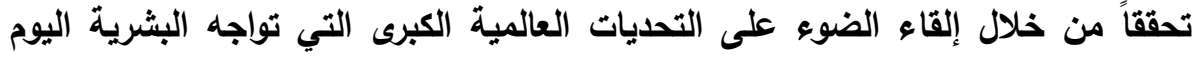

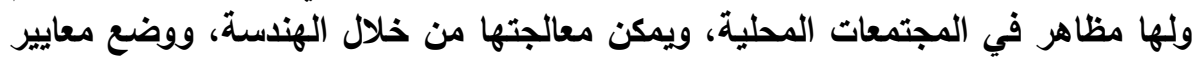

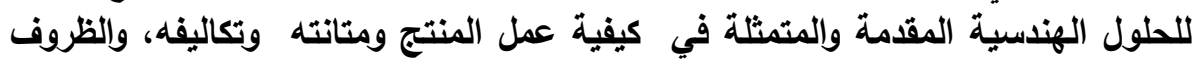

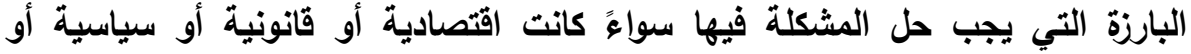

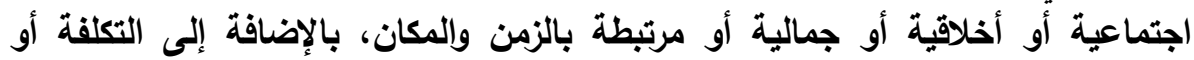

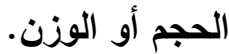

كما تحقق معيار "تطوير الحلول المكنةة" بنسبة مقاربة لمعيار "تعريف وتحديد

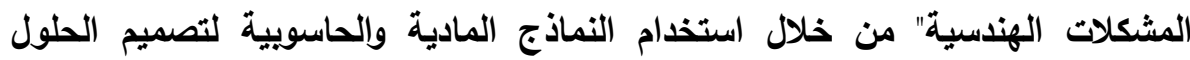

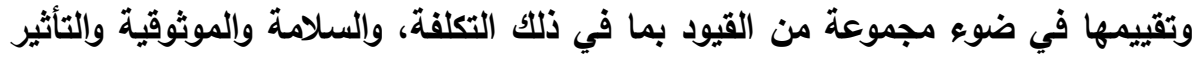

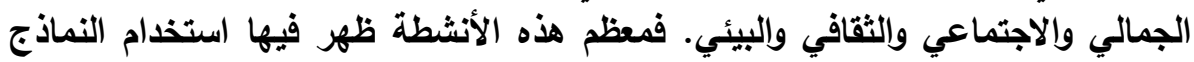

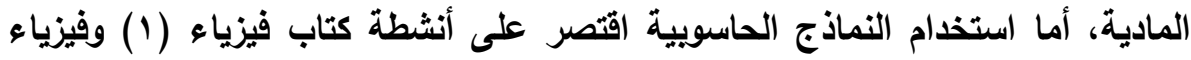

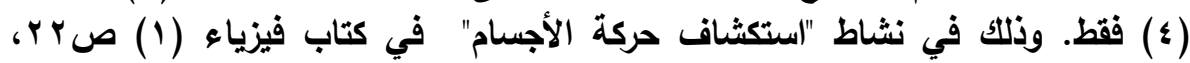

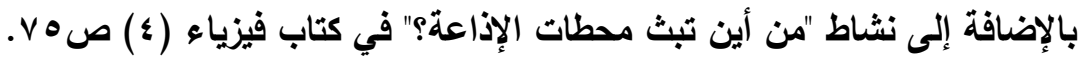

في حين ظهر قصور كبير في تحقق معيار "تحسين حل التصميم" والذي يقوم

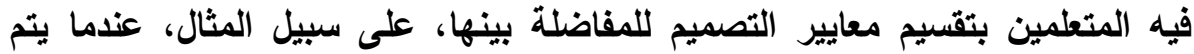
تحسين معيار واحد (مثل الوزن الخفيف)، يمكن التضحية بواحد آخر (مثل تكلفة الوحدة)

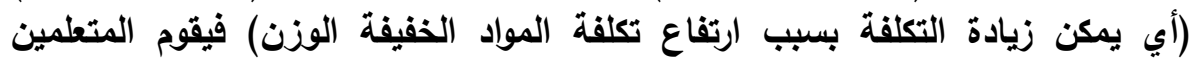
بتخفيض قيمة أحد المعايير أو استبدالها بآخر يعتبر أكثر أهمية.

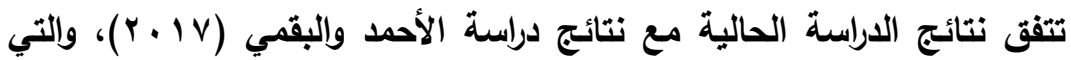
أظهرت نتائجها أنّ معيار "تعريف وتحديد المشكلات الهندية" تحقق بنسبة منذفضة جداً

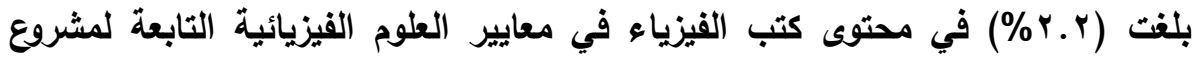

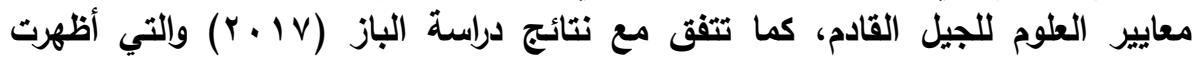


نتائجها أن معيار "تعريف وتحديد المشكلات الهندسية" تحقق بنسبة تضمين ضعيفة جداً

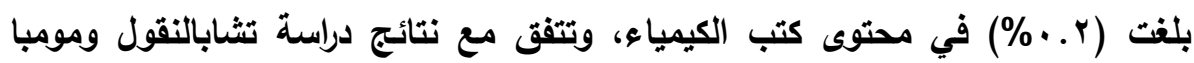

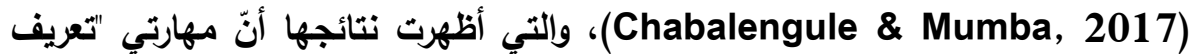

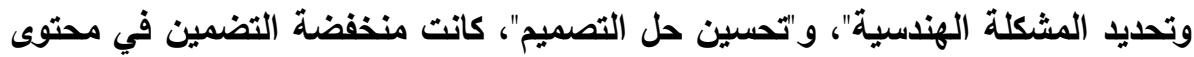

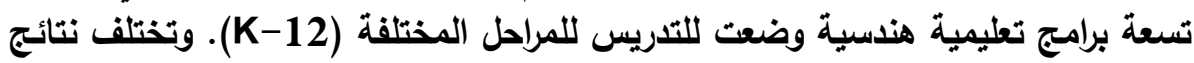

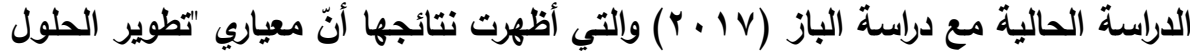
المكنة" و "تحسين حل التصميز"، لم يتحققا في محتوى منهج الكيمياء.

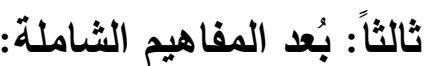

يتضح من الجدول (0)، أنّ معايير التصميم الهندسي في بعد المفاهيم الثاملة

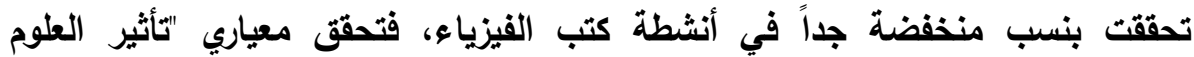

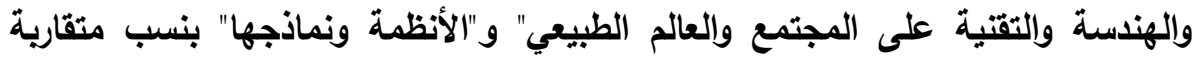

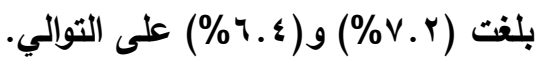

جدول (•): التكرارات والنسب المئوية لمعايير التصميم الهندسي في بُعد المفاهيم الثناملة

\begin{tabular}{|c|c|c|c|}
\hline \multicolumn{2}{|c|}{ المعايير } & " & \multirow[b]{2}{*}{ الكتاب } \\
\hline تأثير العجتمع والهنالمة الطبيعي & الأنظمة ونماذجها & $\%$ & \\
\hline 1. & $v$ & ت & \multirow{2}{*}{ ثيزياء (1) } \\
\hline$\% 1 . r$ & $\% . .9$ & $\%$ & \\
\hline ir & 1. & ت & \multirow{2}{*}{ فيزياء (Y) } \\
\hline$\% 1.7$ & $\% 1 . r$ & $\%$ & \\
\hline 11 & 11 & ت & \multirow{2}{*}{ يزياء (r) } \\
\hline$\%$ \%.\& & $\%$ \%.\& & $\%$ & \\
\hline $1 \varepsilon$ & ir & ت & \multirow{2}{*}{ يزياء (؛ ) } \\
\hline$\% 1.9$ & $\%$ \%.v & $\%$ & \\
\hline $0 \leqslant$ & $\leq \wedge$ & ت & المجموع \\
\hline$\% \vee . r$ & $\%$ \%. & $\%$ & \\
\hline
\end{tabular}




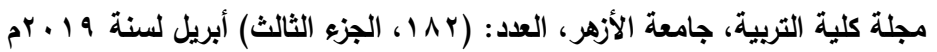

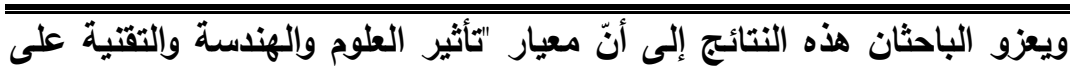

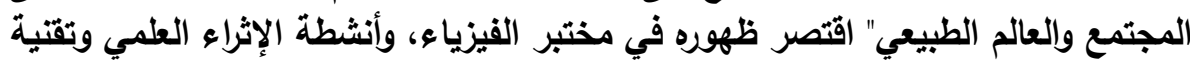

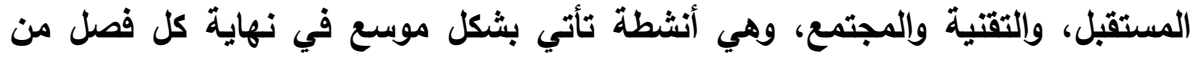

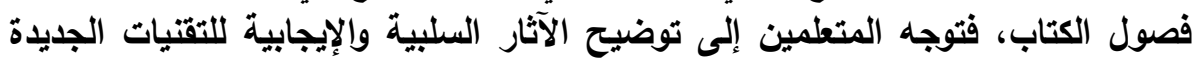

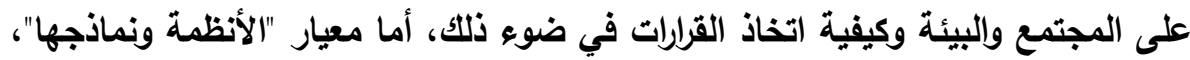

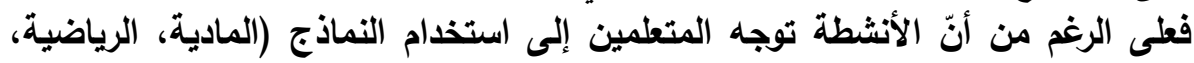

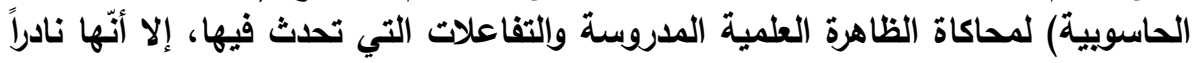

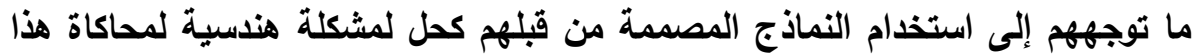
النظام -الحل المصمم - وإلتنبؤ بسلوكياته وكيفية تفاعله مع الأنظمة الأخرى.

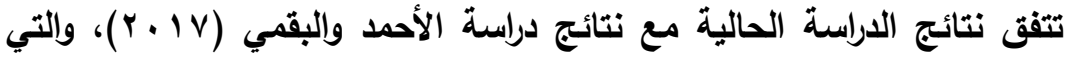

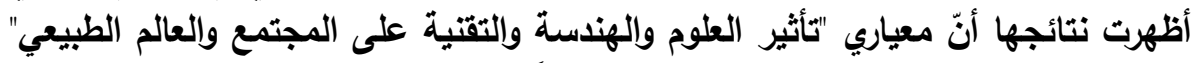

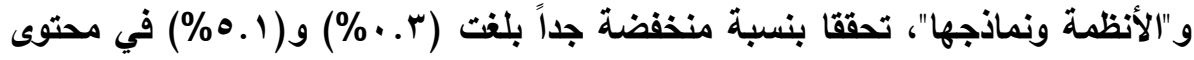
كتب القيزياء في معايير العلوم الفيزيائية التابعة لمشروع معايير العلوم للجيل القائلة القادم، كما

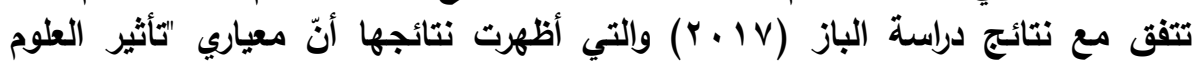
والهندة والتقتية على المجتمع والعالم الطبيعي" و"الأنظمة ونماذجها"، تحققا بنسبة

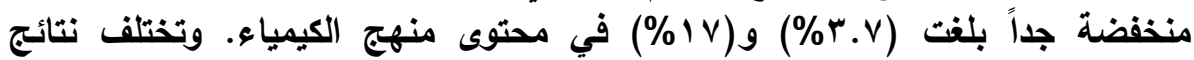

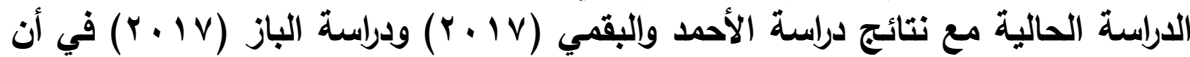
معيار "تأثير العلوم والهندسة والتقتية على المجتمع والعالم الطبيعي" أكثر تحققاً من معيار

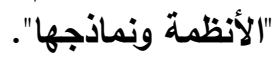

كما أنّه باستقراء نتائج الجدول (r) و (ع) و(•) يظهر أنّ هناك تباين في

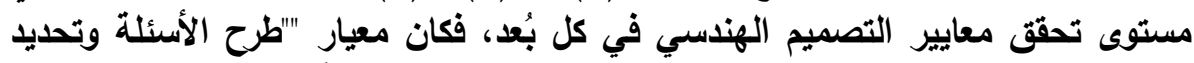

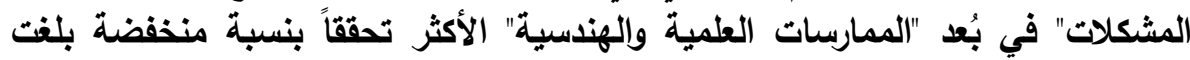

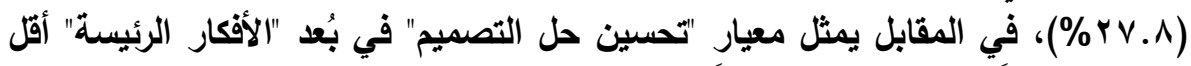

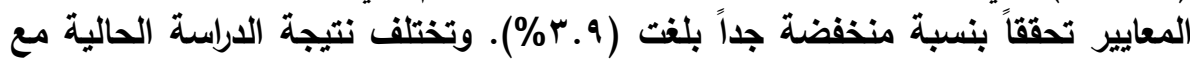

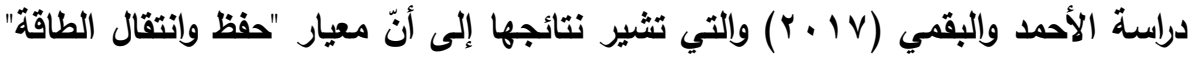

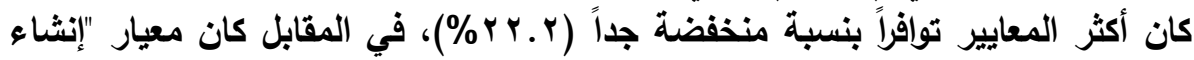
الايضاحات وتصميم الحلول" أقل المعايير توافراً في محتوى منهاج الفيزياء للمرحلة

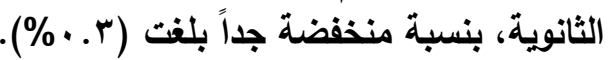




\section{نتائج ومناقثة السؤال الثاني:}

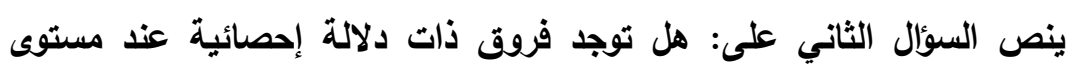

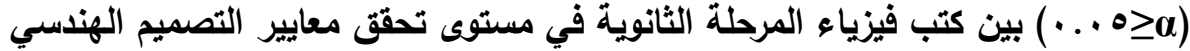

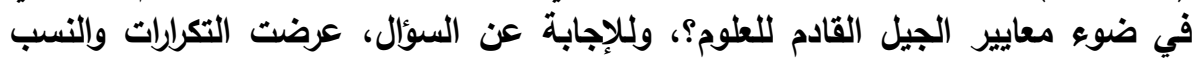

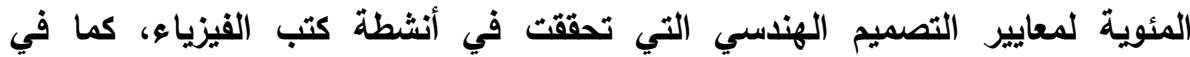

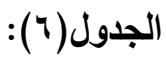

جدول (†): التكرارات والنسب المئوية لمعايير التصميم الهندي لكل كتاب

\begin{tabular}{|c|c|c|c|c|c|c|c|c|c|}
\hline \multicolumn{2}{|c|}{ فيزياء (ع) } & \multicolumn{2}{|c|}{ فيزياء (r) } & \multicolumn{2}{|c|}{ فيزياء (Y) } & \multicolumn{2}{|c|}{ فيزياء (1) } & \multirow{2}{*}{ المعيار } & \multirow{2}{*}{ r } \\
\hline$\%$ & $ت$ & $\%$ & $ت$ & $\%$ & $ت$ & $\%$ & $ت$ & & \\
\hline$\% \curlyvee \wedge . \varepsilon$ & Or & |\%ห५.६ & 7. & $\% \curlyvee \wedge . r$ & Or & $\% \curlyvee \wedge . \varepsilon$ & $\leqslant r$ & طرح الأسئلة وتحديد & 1 \\
\hline$\% \wedge . \vee$ & 17 & $\%$ \%.r & r1 & $\% 10$ & $\mathrm{rA}$ & $\% \backslash \wedge . \uparrow$ & rV & استخذام الرياضيات & $r$ \\
\hline$\% 17.9$ & $\mu_{1}$ & \%) $1 \leq .0 \mid$ & $r r$ & 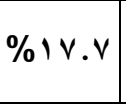 & $r \mu$ & $\% 17.9$ & ro & بناء التفسيرات وتصميم & $r$ \\
\hline$\% \backslash \leq . Y$ & Y & $\% 1 \leq .0 \mid$ & $r r$ & $\% \backslash$ Y.r & $r \mu$ & $\%, Y, Y$ & 11 & تعريف وتحليد المشكلات & $\varepsilon$ \\
\hline$\% \backslash \leq . Y$ & Y4 & $\% 1 \leqslant$ & $r Y$ & $\% 1 \cdot .7$ & $r \cdot$ & $\% 1 \cdot .1$ & 10 & تطوير الحلول المكنة & ० \\
\hline \%r.r & 7 & $\%\{. \wedge$ & 11 & $\% \leq . r$ & $\wedge$ & $\%$ \%.V & $\varepsilon$ & تحسين حل التصميم & 7 \\
\hline$\% \vee .1$ & 14 & $\% \vee .9$ & 11 & $\% \bullet . r$ & $1 \cdot$ & $\%$ \%.V & $\mathrm{V}$ & الأنظمة ونماذج الأنظمة & $\mathrm{v}$ \\
\hline$\% \vee . \vee$ & $1 \leq$ & $\% \vee . q$ & 11 & \%ч.ร & $1 Y$ & $\%$ \%.А & 1. & تأتثير العلوم والهندسة & $\Lambda$ \\
\hline $1 \wedge r$ & & YYV & & IAv & & $1 \leqslant 1$ & & المجموع & \\
\hline
\end{tabular}

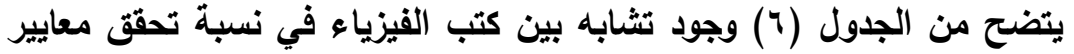

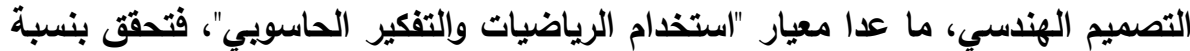
(Y.Y)

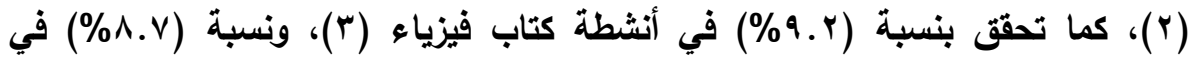
أنثطة كتاب فيزياء (؟))، وقد يعود هذا التباين إلى التباين في طبيعة الأنثطة المقررة 


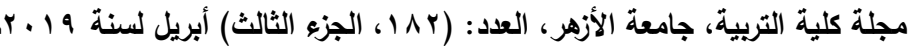

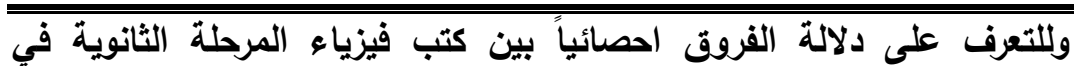

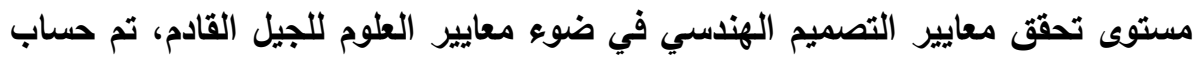
(كا"r) كما هو مبين في الجدول (V) جدول (v): قيم (كاץ) ودلالة الفروق بين كتب الفيزياء في مستوى تحقى معايير التصميم الهندسي.

\begin{tabular}{|c|c|c|c|c|c|c|c|c|c|}
\hline \multicolumn{9}{|c|}{ معايير التصميم الهندسي } & \multirow[b]{2}{*}{ لكتاب | } \\
\hline والتأثير العلوم & ونماذجها & تحل حسين & الطوير & المشعيف & تلفسيرات & الرالتفكير & المشكلات & التكرار | & \\
\hline 1. & v & $\varepsilon$ & 10 & 11 & ro & $r v$ & $\varepsilon r$ & الملاحظ & \multirow{2}{*}{ فيزياء } \\
\hline $1 \% .0$ & Ir & V.r & rr.r & ro & $r . .0$ & $r r$ & 01.1 & المتوقع | & \\
\hline Ir & 1. & $\Lambda$ & $r \cdot$ & rr & $r r$ & $r \wedge$ & or & الملاحظ & \multirow{2}{*}{$\begin{array}{l}\text { فيزياء } \\
\text { (r) }\end{array}$} \\
\hline $1 \pi .0$ & Ir & V.r & rr.r & ro & $r \cdot . \Delta$ & $r r$ & 01.1 & المتوقع | & \\
\hline 11 & 11 & 11 & rr & $r r$ & $r r$ & $r_{1}$ & 7. & الملاحظ & \multirow{2}{*}{ فيزياء } \\
\hline $1 \pi .0$ & Ir & V.r & rr.r & ro & $r . .0$ & $r r$ & 01.1 & المتوقع | & \\
\hline $1 \varepsilon$ & ir & 7 & rq & rq & $\mu$ & 17 & Or & الملاحظ & \multirow{2}{*}{ فيزياء } \\
\hline $1 T .0$ & Ir & V.r & YT.r & ro & $r . .0$ & Tr & 01.1 & المتوقع | & \\
\hline r.oq & 0.0 & r.79 & V & $\varepsilon . V Y$ & $1 . \leqslant 1$ & $\{. . \wedge$ & $r .1 \Lambda$ & \multicolumn{2}{|c|}{ Sis } \\
\hline$\because \leqslant 0$ &. $.1 \pi$ & .rq & $\ldots v$ &. .19 & $\therefore v$. & .ro & r. & \multicolumn{2}{|c|}{ مستوى الدلالة } \\
\hline
\end{tabular}

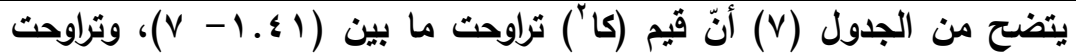

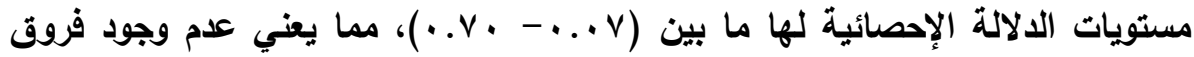

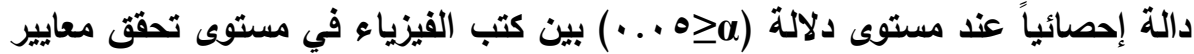
التصميم الهندسي في ضوء معايير الجيل القادم لتعليم العلوم.

ويعزو الباحثان هذه النتيجة إلى أن كتب الفيزياء تمثل المنتجات التعليمية لمشروع تطوير العلوم والرياضيات في المملكة العربية السعودية، والتي تمثل في نسخها $-494-$ 


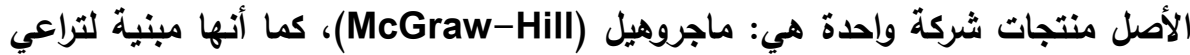

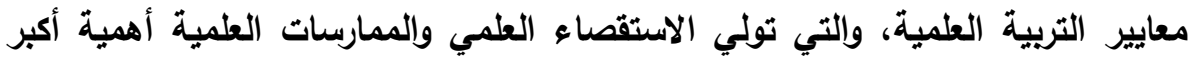

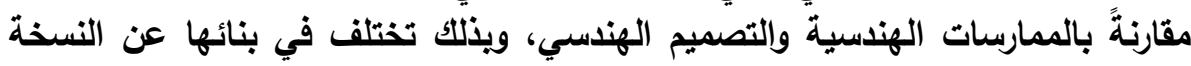

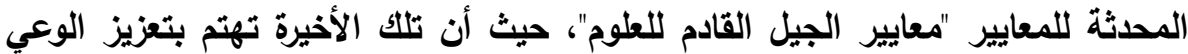

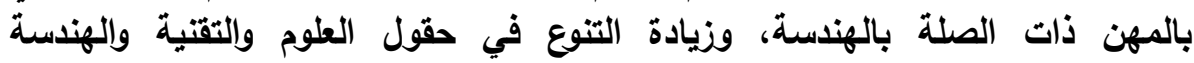
والرياضيات، تزويد المتعلمين بمهارات STEM من خلال إشراكهم في حل المشكيات فئلات الهناسية بواسطة التصميم الهنلسي. تئين

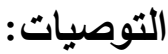

في ضوء نتائج الاراسة الحالية، خرج الباحثان بالتوصيات التالية:

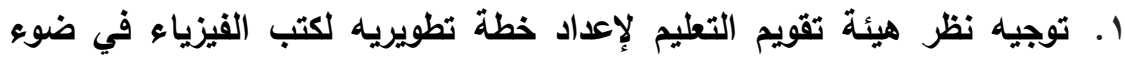

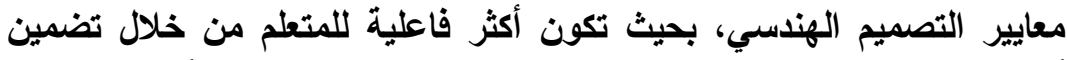

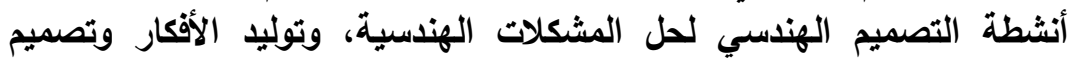

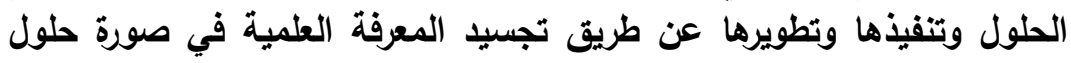

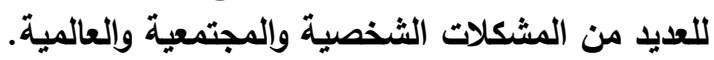

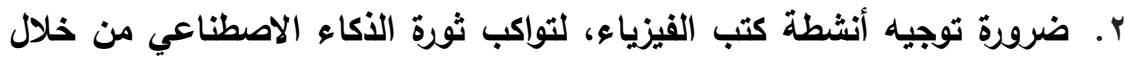
ممارسة الاستقصاء والتحقيق العلمي بصورة أعمق، والرقي بهاء إلى مستوى التصميم التقني والاتتاج المادي.

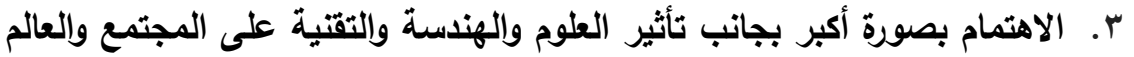

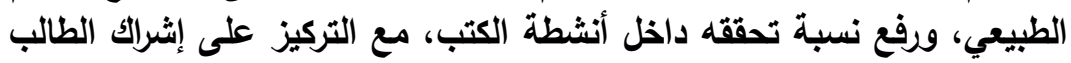
في تصور التأثير ونمذجته وتصميمه وتقييمه. المقترحات: - ات

1. إجراء مزيد من الدراسات التحليلية لكتب العلوم المختلفة في مراحل التعليم العام،

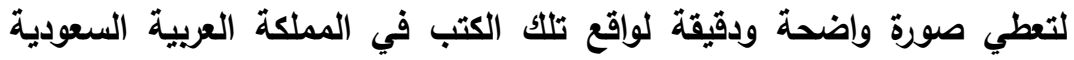
ومستوى تحقيقها لمعايير التصميم الهندسي بمشروع معايير الجيل الثقادم للعلوم التهاية

(NGSS) r. إجراء دراسة مسحيَّة للتعرُّن على تصورات مطلمي العلوم عن معايير التصميم الهندسي. 


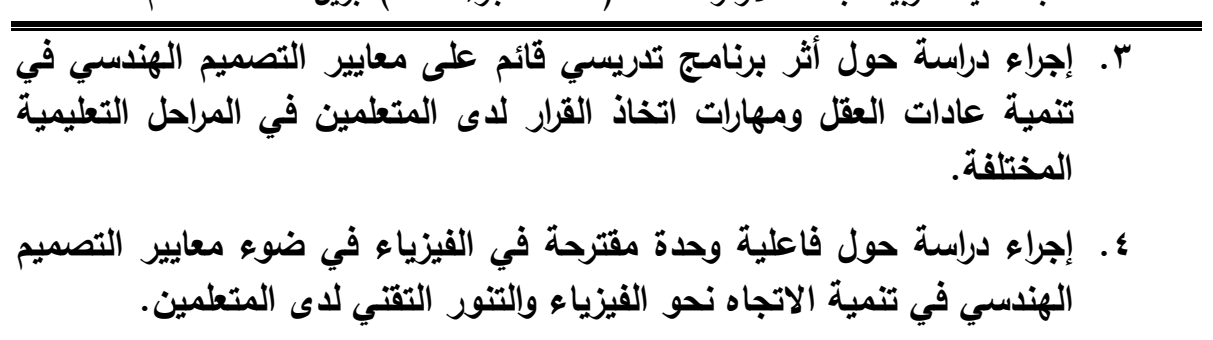




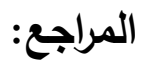

أولاً: المراجع العربية:

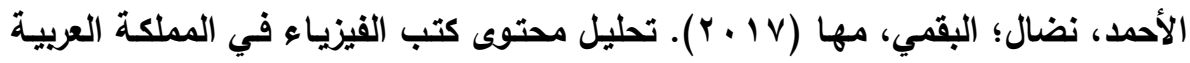

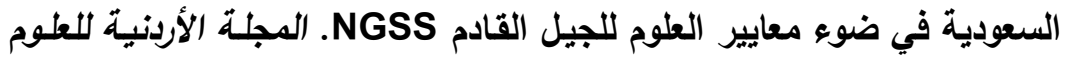

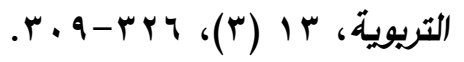

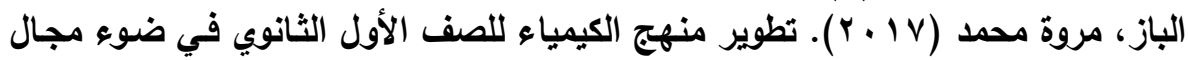

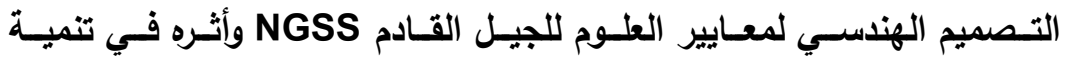

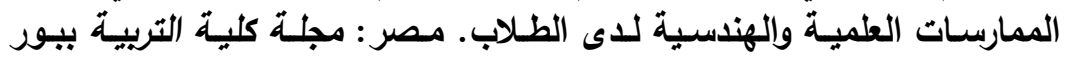

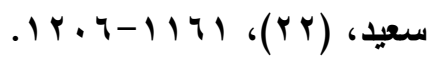

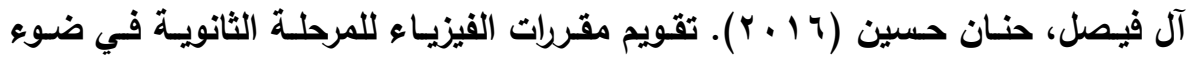

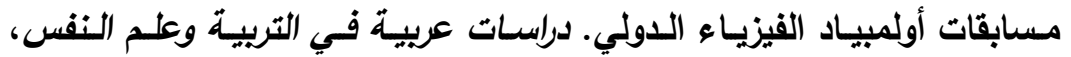

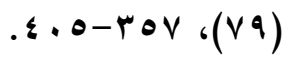

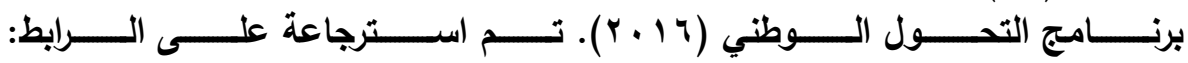
(http://vision2030.gov.sa)

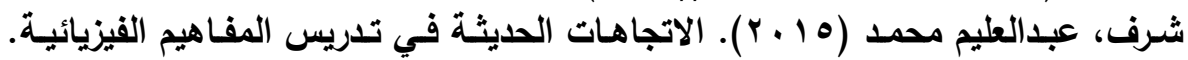

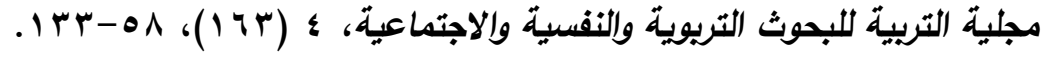

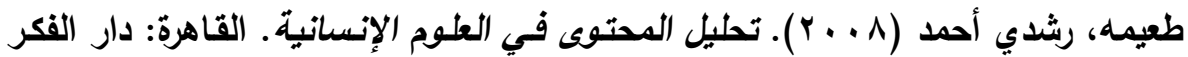
العربي. - العمئ عبدالسلام، مصطقى عبدالسلام (9 . . r). الاتجاهات الحديثة في تلدريس العلوم. القاهرة: دار الفكر العربي.

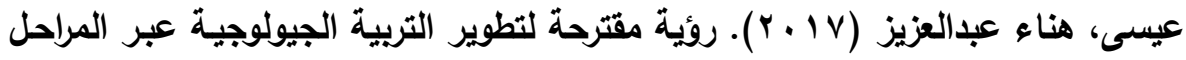

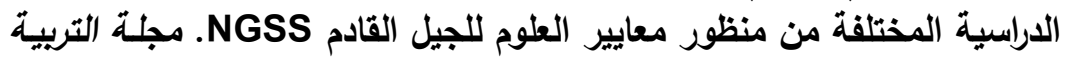

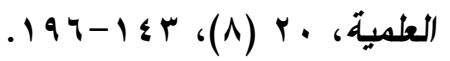

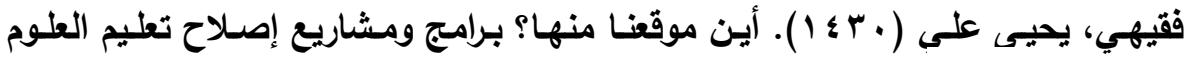

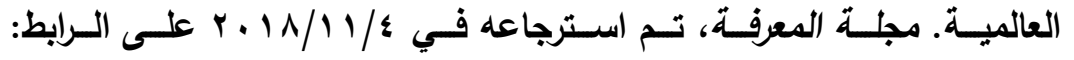

http://www.almarefh.net/show_content

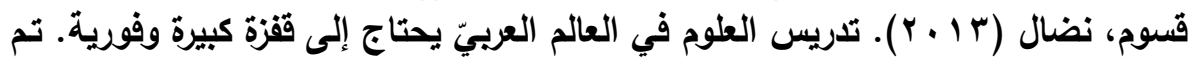

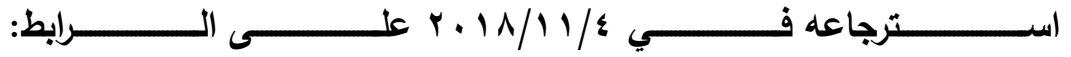

http://blog.icoproject.org/?p=576 


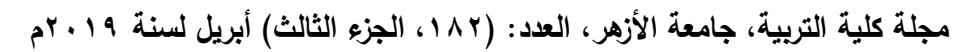

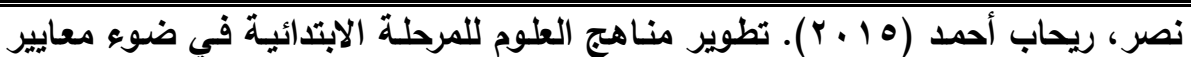

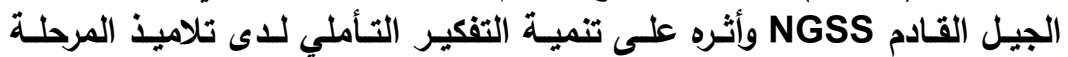

الابتدائية. مجلة الدراسات التريوية والإنسانية، ل V (؟).

$$
\text { ثانياً: المراجع الأجنبية: }
$$

Boesdorfer. SB. (2017). Is Fngineering Insniring Change in Secondarv Chemistrv Teachers' Practices?. IOURNAL OF SCIENCE TEACHER EDUCATION, 28, 609-630

Brophy, S., Klein, S., Portsmore, M., \& Rogers, C. (2008). Advancing engineering education in P-12 classrooms. Journal of Engineering Education, 97, 369- 386

Concannon. I. \& Brown. PI. (2017). Windmills bv design: Purboseful curriculum design to meet next generation science standards in a 9-12 physics classroom, SCIENCE ACTIVITIES, 54, 1-7

Chabalengula. V. \& Mumba. F. (2017). Engineering design skills coverage in K-12 engineering nrogram curriculum materials in the USA. International Journal of Science Education, 39, 2209-2225

Douglas, J., Iversen, E., \& Kalyandurg, C. (2004). Engineering in the K-12 classroom: An analysis of current practices and guidelines for the future. Washington, DC: ASEE Engineering K-12 Center

Granucci. N.. Jenkins. C.. Bauer. M.. Gard. AL.. Pinkerton. B. \& Broadbridge. C. (2017). Teaching Materials Science and Engineering (MSE) in the Pre-College Classroom as a Vehicle for NGSS Implementation, MRS ADVANCES, 2, 1661-1666

Grubbs, M., \& Strimel, G. (2015). Engineering Design: The Great Integrator, Journal of STEM Teacher Education, 50, Iss. 1 , $\begin{array}{lll}\text { Article } & 8 & \text { Available }\end{array}$ at:https://ir.library.illinoisstate.edu/jste/vol50/iss1/8

Granucci. N.. Jenkins. C.. Bauer. M.. Gard. AL.. Pinkerton. B. \& Broadbridge. C. (2017). Teaching Materials Science and Engineering (MSE) in the Pre-College Classroom as a Vehicle for NGSS Implementation, MRS ADVANCES, 2, 1661-1666 
تحليل محتوى كتب الفيزياء في المملكة العربية السعودية في ضوء التصميم الهندسي لمعايير الجيل ...

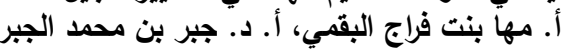

King, D. \& English. L. (2016). Engineering design in the primarv school: anolving stem concents to build an ontical instrument, International Journal of Science Education, 38, 2762-2794

Kristin, L. G. \& Tolbert, S. (2018). The imperative to move toward a dimension of care in engineering education: $J$ Res Sci Teach, 55, 938- 961

Maeng. .I.. Whitworth. B.. Gonczi. A.. Navv. S. \& Wheeler. L. (2017). Elementarv science teachers' integration of engineering design into science instruction: results from a randomised controlled trial. International Journal of Science Education, 39, 1529-1548

National Academy of Engineering and National Research Council (2009). Engineering in K-12 education: Understanding the status and improving the prospects. Washington, DC: National Academies Press. https://www.nap.edu/catalog/12635/engineering-in-k-12education-understanding-the-status-and-improving

National Research Council (2012). A Framework for $k$-12 science education: Practices, crosscutting concepts, and core ideas. Washington, DC: National Academies Press.

NGSS Lead States (2013). APPENDIX I - Engineering Design in the NGSS: For states, by states. Washington, DC; National Academies Press

Peterman. K.. Daughertv. I.. Custer. R. \& Ross. I. (2017). Analvsing the integration of engineering in science lessons with the Engineering-Infused Isesson Rubric, International Journal of Science Education, 39, 1913-1931

Ribeiro, L. R. C. (2011). The pros and cons of problem-based learning from the teacher's standpoint. Journal of University Teaching \& Learning Practice, 8(1), Retrieved from http://ro.uow.edu.au/ jutlp/vol8/iss1/4

Senider, C. (2012). Core Ideas of Engineering and Technology. Nsta's Journal. Retrieved at: http://nstahosted.org/pdfs/ngss/resources/201201 Framewo rk-Sneider.pdf 